\title{
DISPONIBILIDADE DE ENERGIA E NUTRIENTES NOS DOMICÍLIOS DE FAMÍLIAS DAS REGIÕES METROPOLITANAS DE CURITIBA E PORTO ALEGRE
}

\author{
ROZANE APARECIDA TOSO BLEIL
}

Dissertação apresentada à Escola Superior de Agricultura "Luiz de Queiroz", Universidade de São Paulo, para obtenção do título de Mestre em Ciência, Área de Concentração em Ciência e Tecnologia de Alimentos.

\author{
P I R A C I C A B A \\ Estado de São Paulo - Brasil \\ Julho - 2004
}




\title{
DISPONIBILIDADE DE ENERGIA E NUTRIENTES NOS DOMICÍLIOS DE FAMÍLIAS DAS REGIÕES METROPOLITANAS DE CURITIBA E PORTO ALEGRE
}

\section{ROZANE APARECIDA TOSO BLEIL}

\author{
Nutricionista
}

Orientadora: Profa. Dra. MARINA VIEIRA DA SILVA

Dissertação apresentada à Escola Superior de Agricultura "Luiz de Queiroz", Universidade de São Paulo, para obtenção do título de Mestre em Ciência, Área de Concentração em Ciência e Tecnologia de Alimentos.

\author{
P I R A C I C A B A \\ Estado de São Paulo - Brasil \\ Julho - 2004
}




\section{Dados Internacionais de Catalogação na Publicação (CIP) DIVISÃO DE BIBLIOTECA E DOCUMENTAÇÃO - ESALQ/USP}

Bleil, Rozane Aparecida Toso

Disponibilidade de energia e nutrientes nos domicílios de famílias das regiões metropolitanas de Curitiba e Porto Alegre / Rozane Aparecida Toso Bleil. - - Piracicaba, 2004

87 p. : il.

Dissertação (mestrado) - - Escola Superior de Agricultura Luiz de Queiroz, 2004.

Bibliografia.

1. Consumo alimentar 2. Macronutrientes 3. Micronutrientes 4. Segurança alimentar I. Título

CDD 614.31

"Permitida a cópia total ou parcial deste documento, desde que citada a fonte - O autor" 


\section{DEDICATÓRIA}

À Deus, pela certeza de que foi Dele a força que me incentivou a percorrer este caminho;

Ao Helmuth, que sempre esteve ao meu lado, nos momentos de angústias, alegrias e também de ausências, dedico meu amor, carinho e gratidão;

Aos meus filhos, Fernanda e João Pedro, que com seu jeito carinhoso e alegre souberam aceitar minha ausência neste período;

Aos meus pais, Camila e Romano, que me deram a vida e foram em parte, responsáveis por eu chegar até aqui.

À querida Erna, pelo apoio durante minha ausência de casa. 


\section{AGRADECIMENTOS}

Devo gratidão especial à minha orientadora, Profa. Marina Vieira da Silva, que com sua competência, incentivo, apoio e orientação, muito contribuiu para o meu crescimento científico e pessoal, sempre me orientando ao longo do período de elaboração deste trabalho;

À Escola Superior de Agricultura "Luiz de Queiroz", por possibilitar o meu aperfeiçoamento profissional;

Aos professores e funcionários do Departamento de Alimentos, Agroindústria e Nutrição, pelo apoio no decorrer deste período;

À Banca do Exame de Qualificação, Profa. Dra Gilma Lucazechi Sturion, Profa. Dra Kátia Cilene Tabai e Profa. Dra Marta Helena Fillet Spoto, pelas valiosas sugestões para o trabalho;

Á FAPESP, pela liberação de recursos para a pesquisa intitulada Os padrões de alimentação do Brasil Urbano (Proc. 1999/11099-9), coordenada pela Profa. Marina Vieira da Silva, que por meio de um dos sub-projetos viabilizou a realização da presente pesquisa;

Em especial às amigas Daniela Cristina Rossetto Caroba e Michele Sanches, que muito contribuíram e me auxiliaram em meus momentos de dúvidas e dificuldades. 


\section{SUMÁRIO}

Página

LISTA DE QUADROS ................................................................... vi

LISTA DE TABELAS....................................................................... vii

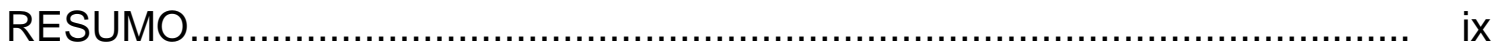

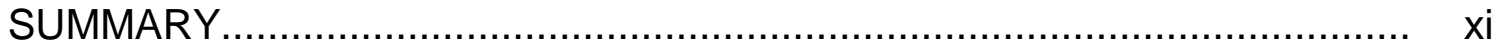

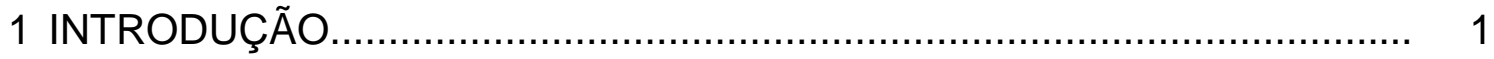

2 REVISÃO DE LITERATURA......................................................... 5

3 MATERIAL E MÉTODOS............................................................. 14

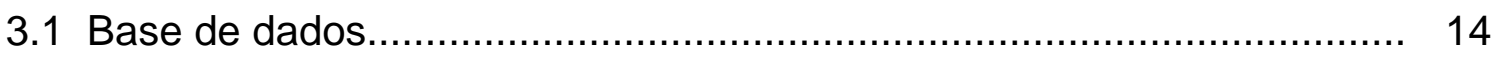

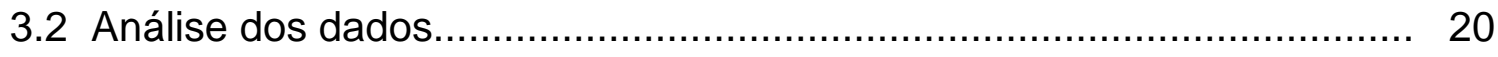

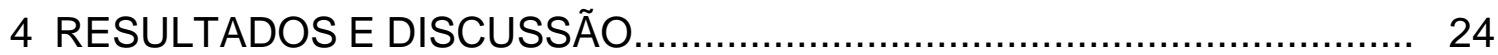

4.1 Análise de energia e macronutrientes............................................... 24

4.2 Análise da participação dos grupos alimentares.................................. 35

4.3 Análise da participação dos alimentos in natura e industrializados......... 45

4.4 Análise da disponibilidade de fibras e colesterol.................................. 48

4.5 Análise da disponibilidade de vitaminas e minerais............................. 51

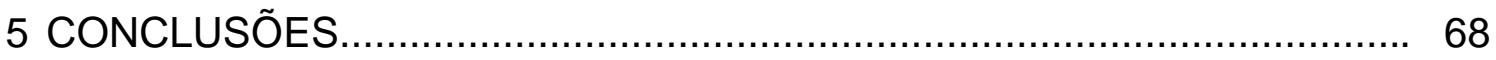

REFERÊNCIAS BIBLIOGRÁFICAS ....................................................... 72

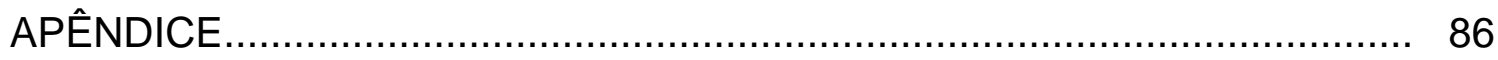




\section{LISTA DE QUADROS}

Página

1 Municípios integrantes das regiões metropolitanas de Curitiba e

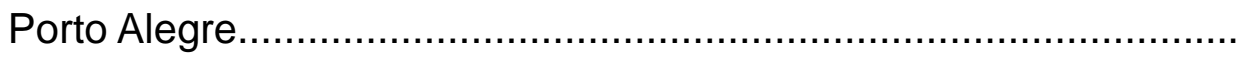

2 Características econômicas e demográficas das famílias pertencentes às regiões Metropolitanas de Curitiba e Porto

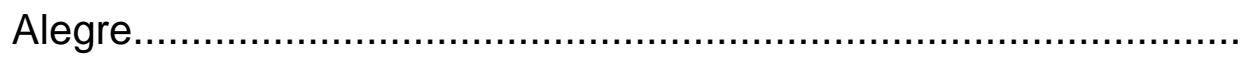

3 Domicílios "esperados, selecionados e entrevistados" segundo as

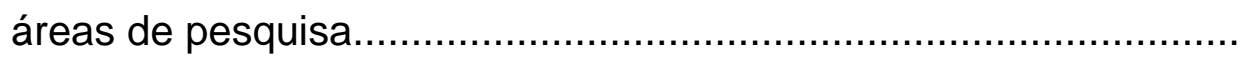

4 Valor da despesa média mensal familiar com alimentação no

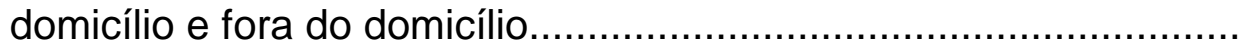

5 Recomendações (média) de ingestão de vitaminas e minerais........ 


\section{LISTA DE TABELAS}

Página

1 Disponibilidade de energia e participação dos macronutrientes (proteínas, carboidratos e lipídios) nos domicílios das regiões Metropolitanas de Curitiba e Porto Alegre, de acordo com o recebimento familiar per capita......................................................

2 Participação relativa (\%) de proteínas, nos domicílios de Curitiba e Porto Alegre, de acordo com a origem (animal e vegetal) e estratos de recebimento familiar, 1995/1996..................................

3 Participação relativa (\%) dos grupos alimentares no VET diário dos indivíduos das regiões metropolitanas de Curitiba e Porto Alegre, de acordo com o rendimento familiar per capita (em salários mínimos), 1995/1996

4 Participação relativa de alimentos in natura e industrializados (\%) nos domicílios de Curitiba e Porto Alegre, de acordo com o estrato de recebimento familiar, 1995/1996 
5 Disponibilidade diária de fibra (g) e colesterol ( $\mathrm{mg}$ ) nos domicílios das regiões metropolitanas de Curitiba e Porto Alegre, de acordo com o recebimento familiar per capita (em salários mínimos), $1995 / 1996$

6 Disponibilidade de vitaminas nos domicílios das regiões metropolitanas de Curitiba e Porto Alegre (POA), de acordo com o estrato de recebimento familiar per capita (em salários mínimos), de até 2 SM até mais de 6 a 8 SM, 1995/1996.

7 Disponibilidade de vitaminas nos domicílios das regiões metropolitanas de Curitiba e Porto Alegre (POA), de acordo com o estrato de recebimento familiar per capita (em salários mínimos), de mais de 8 a 10 SM até mais de 30 SM, 1995/1996....

8 Disponibilidade de minerais nos domicílios das regiões metropolitanas de Curitiba e Porto Alegre (POA), de acordo com o estrato de recebimento familiar per capita (em salários mínimos), de até 2 SM até mais de 6 a 8 SM, 1995/1996.

9 Disponibilidade de minerais nos domicílios das regiões metropolitanas de Curitiba e Porto Alegre (POA), de acordo com o estrato de recebimento familiar per capita (em salários mínimos) de mais de 8 a 10 SM até mais de 30 SM, 1995/1996 


\title{
DISPONIBILIDADE DE ENERGIA E NUTRIENTES NOS DOMICÍLIOS DE FAMÍLIAS DAS REGIÕES METROPOLITANAS DE CURITIBA E PORTO ALEGRE
}

\author{
Autora: ROZANE APARECIDA TOSO BLEIL \\ Orientadora: Profa. Dra. MARINA VIEIRA DA SILVA
}

\section{RESUMO}

O consumo de alimentos é influenciado, entre outros fatores, pelo processo de urbanização, as políticas agrícolas, a disponibilidade de alimentos, a distribuição de renda, o processamento inadequado, tradições culturais e a propaganda. Em decorrência de desequilíbrios nos elos existentes entre essas variáveis, podem ser observadas, freqüentemente, conseqüências negativas à saúde da população, tais como a desnutrição, obesidade e doenças crônicas. $O$ presente trabalho foi realizado, tendo por base os dados da Pesquisa de Orçamentos Familiares (POF-1995/1996), relativos à amostra da população residente nas regiões metropolitanas de Curitiba e Porto Alegre, pertencentes à Região Sul do Brasil. Os objetivos foram analisar, no âmbito dos domicílios, a disponibilidade de energia e a participação dos macronutrientes no Valor Energético Total - VET; analisar a oferta de proteínas quanto à sua origem (animal ou vegetal); analisar a disponibilidade de fibras, colesterol, vitaminas e minerais nos domicílios da referida população; analisar a disponibilidade de 
alimentos quanto a sua origem (industrializados e in natura) e também a participação dos grupos alimentares no VET diário das famílias. Para os cálculos nutricionais foi utilizado o software Virtual Nutri (Phillippi, 1996). Adotou-se como parâmetro, as recomendações de energia, macro e micronutrientes, os valores preconizados pela National Academy of Sciences (2003). Os resultados mostram que a disponibilidade de energia e macronutrientes para estes grupos populacionais pode ser considerada adequada. Por outro lado, a participação da proteína de origem animal revelase elevada para a totalidade das famílias. Em relação ao colesterol os resultados apresentam-se abaixo dos valores preconizados. Ressalva-se que a presente pesquisa não avaliou o consumo de alimentos fora do domicílio. Considerando a disponibilidade de fibras para as famílias da amostra, infere-se que a mesma é insuficiente. Em relação aos micronutrientes, observa-se uma baixa disponibilidade, dos seguintes nutrientes: ácido fólico, niacina, vitamina B12, cálcio, ferro, zinco, magnésio e selênio. Em relação aos grupos alimentares, merece destaque a maior participação do grupo das leguminosas, especialmente o feijão, no VET (disponível nos domicílios) das famílias mais pobres. Por outro lado, observa-se aumento na disponibilidade do grupo das carnes e embutidos e do leite e derivados, conforme ocorre incremento da renda, o que ressalta a influência desta na aquisição de alimentos. Não é identificada diferença expressiva na participação de hortaliças no VET, quando se considera concomitante, as famílias dos diferentes estratos de renda e as duas regiões metropolitanas. Por outro lado, a participação das frutas mostra tendência crescente, conforme aumenta a renda. Há um predomínio de produtos industrializados no VET, quando se considera a totalidade das famílias integrantes da pesquisa. A renda e os hábitos culturais parecem exercer influência decisiva nos hábitos alimentares da população observada. Face ao exposto é fundamental que se busquem estratégias, que adotadas em curto espaço de tempo, contribuam de forma decisiva para a melhoria dos hábitos e o padrão de consumo alimentar da referida população. 


\title{
ENERGY AND NUTRIENTS AVAILABILITY IN DWELLING FAMILIES FROM CURITIBA AND PORTO ALEGRE METROPOLITAN AREAS
}

\author{
Author: ROZANE APARECIDA TOSO BLEIL \\ Adviser: Profa. Dra. MARINA VIEIRA DA SILVA
}

\section{SUMMARY}

The food consumption is influenced, among other factors, by the process of urbanization, agricultural policies, food availability, income distribution, adequate processing, feeding habits and marketing. In the course of this interaction, negative consequences may be observed in the state of health, such as malnutrition, obesity and chronic illnesses. The present study was accomplished using the Family Budgetary Survey (FBS-1995/1996) data base, related to the metropolitan areas of Curitiba and Porto Alegre -southern Brazil. The objectives were to analyze the families accessibility to energy and the participation of macronutrients in the Total Calorie Value-TCV available in the domicile; to differentiate the protein origin (animal or vegetal); to estimate the amounts of dietary fiber, cholesterol, vitamins, and minerals at the household's disposal in the referred population; to determine the food accessibility according to the extent of transformation (manufactured or in natura) and also, the participation of each food group at the families' disposal, according to the daily TCV. The software Virtual Nutri (Phillippi, 1996) was used to calculate nutrient 
availability. Energy, macro and micronutrient recommendations by the National Academy of Sciences (2001) were adopted as parameters. The results showed that the energy and macronutrients at the disposal of these population groups may be considered adequate. On the other hand, the study revealed elevated participation of animal protein for the totality of families. Cholesterol, however, appeared to be present at amounts lower than recommended, notwithstanding the fact that this research did not take into account the food consumed outside the domicile. Considering the dietary fiber at the disposal of these families, we can infer it was insufficient. In relation to micronutrients, we observed a low availability, especially for folic acid, niacin, vitamin B12, calcium, iron, zinc, magnesium and selenium. In relation to the food groups, the participation of legumes, especially beans, on the TCV of the household of the poorest families was outstanding. On the other hand, we observed an increase in the access to meat and poultry, and milk and milk products, concordant with the rising of income, which reinforces the influence of income on food acquisition. The participation of potherbs greens did not present any meaningful difference when the income stratum and metropolitan area were considered. The participation of fruits appeared with an increasing tendency, in relation to income. There was yet the predominance of manufactured food products on the TCV for the totality of families surveyed. It may be concluded that both income and cultural habits seem to exert decisive influence on the food habits of this population. Thus, it is fundamental to search for alternatives in order to improve the habits and consumption patterns of the referred population, independent of their socioeconomical or cultural backgrounds. 


\section{INTRODUÇÃO}

Durante os anos 80 e meados dos anos 90 a economia brasileira se caracterizou por uma forte instabilidade no ritmo de crescimento, com taxas de inflação alcançando patamares extremamente elevados. Em decorrência dos referidos episódios, em 1994 foi implantado o Plano de Estabilização, conhecido como "Plano Real". Com a estabilidade monetária, a metade mais pobre da população incrementou sua participação na renda nacional. O Produto Interno Bruto (PIB) aumentou 7,4\% entre 1994 e 1996, passando de U\$ 662.000 milhões para U\$ 711.000 milhões, com um aumento do PIB per capita de U\$ 4.305 a U\$ 4.503. Em 1996 a inflação anual foi de 9,8\%, enquanto que no início do plano de estabilização, o índice alcançava a média mensal de $45 \%$ (Organização Panamericana de Saúde, 2001).

No que tange às condições nutricionais da população brasileira, de acordo com a Organização Panamericana de Saúde - OPAS (2001), ao longo das últimas décadas tem sido verificada uma redução progressiva da desnutrição infantil, especialmente entre os menores de 5 anos. Neste mesmo período a proporção de adultos obesos quase dobrou (de 5,7\% a 9,6\%). Em 1989, a obesidade superou a desnutrição entre as mulheres de todos os níveis de renda e entre os homens pertencentes aos estratos de rendimentos médio e alto.

De acordo com Tirapegui (2000), o consumo de alimentos, tanto em quantidade como em qualidade, ocorre devido a inúmeros fatores, entre os quais destacam-se: o processo acelerado de urbanização; as políticas agrícolas adotadas pelo governo, por vários governos, que pouco estimulam a produção 
de alimentos essenciais ao consumo da população brasileira; a disponibilidade de alimentos decorrente entre outros fatores, de problemas de distribuição, armazenamento e sazonalidade; a distribuição inadequada de renda existente no País que dificulta o acesso aos alimentos por grande parcela da população; adoção de práticas de processamento inadequado de alimentos que reduz o teor de nutrientes; os hábitos culturais que contribuem para maior ou menor consumo de certos alimentos e a propaganda, que muitas vezes leva o consumidor a adquirir produtos pouco saudáveis e com custo elevado. Em decorrência da interação dos referidos fatores, podem ser observadas conseqüências como a desnutrição, que está intimamente relacionada com deficiência protéico-energética, de vitaminas e minerais, bem como a obesidade, a qual tem forte associação com doenças cardiovasculares, hipertensão, diabetes, neoplasias, distúrbios gastrointestinais e transtornos alimentares, com redução da capacidade produtiva, aumento nos custos sociais e redução da qualidade de vida da população.

Diversas pesquisas também têm sugerido que os hábitos alimentares da população brasileira sofreram várias transformações, causando impactos nem sempre positivos sobre o estado de saúde e nutrição (Fornes et al., 2000; Lima et al., 2000; Monteiro, Mondini e Costa, 2000; Bleil, 1998; Silva, 1998; Craig, 1997).

Segundo Monteiro, Mondini \& Costa (2000) a análise de dados registrados pelas Pesquisas de Orçamentos Familiares (POF), obtidos por meio da realização de inquéritos domiciliares com levantamento dos gastos com alimentação e dos preços pagos pelos consumidores (integrantes da amostra), permitem estimar a disponibilidade individual de alimentos de cada domicílio. Assim como muitas pesquisas do gênero, a POF possui limitações, pois não considera o desperdício de alimentos, nem os alimentos que foram doados ou adquiridos e consumidos fora do domicílio. As referidas pesquisas também não trazem informações sobre a distribuição de alimentos entre os membros da família. As limitações citadas também prejudicam a aferição, com precisão, da 
quantidade absoluta de alimentos consumidos pelas famílias. Porém a inexistência de outras pesquisas mais completas, como é o caso do Estudo Nacional de Despesa Familiar (ENDEF), realizada entre os anos de 1974 e 1975 (considerada a mais completa), reforça a argumentação da utilização dos dados obtidos pelo Instituto Brasileiro de Geografia e Estatística (IBGE), por meio da POF. Os resultados permitem a visão, ainda que abrangente da disponibilidade de alimentos, o que seguramente pode contribuir para a busca de estratégias que visem a melhoria da situação nutricional da população brasileira.

Quando se considera a região geográfica do Brasil, verifica-se que a Região Sul apresenta a menor área, com $577.214,0$ km² ocupando apenas $6,75 \%$ do território do país. Formada pelos estados do Paraná, Santa Catarina e Rio Grande do Sul, é considerada uma região predominantemente agrícola, com alguns pólos industriais principalmente nas regiões metropolitanas das capitais do Paraná e Rio Grande do Sul. Nesta região são encontrados traços marcantes da influência da imigração alemã, italiana e açoriana (Organização Panamericana de Saúde, 2001).

Face ao exposto, reconhece-se a importância de identificar e analisar a disponibilidade de alimentos para as famílias da população da Região Sul, estabelecendo relação com a renda familiar per capita. Observa-se ainda, escassa disponibilidade de informações que avaliem o consumo alimentar da população da referida região geográfica, bem como a análise temporal desta evolução, o que reforça as justificativas para a implementação da pesquisa.

Portanto, os principais objetivos do presente trabalho são: analisar a disponibilidade nos domicílios, de energia e a participação dos macronutrientes no Valor Energético Total - VET para as famílias; analisar a oferta de proteínas quanto a sua origem (animal ou vegetal); analisar a disponibilidade de vitaminas e minerais para a população; descrever a participação relativa de grupos de alimentos no VET e também, avaliar a disponibilidade de alimentos quanto a 
sua origem (industrializados e in natura) para a população da Região Sul do País. 


\section{REVISÃO DE LITERATURA}

Segundo Valente (1997) o direito a alimentação é concebido como a "garantia a todos os cidadãos do direito ao acesso diário a alimentos em quantidade e qualidade suficientes para atender as necessidades nutricionais básicas, essenciais para a manutenção da saúde". O conceito incorpora também o direito humano de acesso aos recursos e meios para produzir ou adquirir alimentos seguros e saudáveis, que possibilitem uma alimentação de acordo com os hábitos e práticas alimentares de sua cultura, região ou origem étnica.

Nos primórdios das organizações humanas, a alimentação da população constituía-se basicamente da "rudimentar" produção rural, que abastecia alguns povos nômades ou aqueles grupos que viviam em pequenas áreas rurais. A produção de alimentos básicos era essencialmente a produção para o autoconsumo. Atualmente, $75 \%$ da população de países desenvolvidos e $38 \%$ da população de países em desenvolvimento, vivem em áreas urbanas (Food and Agriculture Organization - FAO, 2000).

Vários fatores têm afetado o nível de segurança alimentar e nutricional ${ }^{1}$ em diversos países e inúmeras cidades, entre eles os baixos níveis de renda, a falta de acesso aos alimentos, os altos preços relativos dos alimentos e as condições climáticas desfavoráveis que diminuem a produção de alimentos em

\footnotetext{
${ }^{1}$ Segurança alimentar e nutricional consiste em garantir a todos os indivíduos, condições de acesso a alimentos básicos, seguros e de qualidade, em quantidade suficiente, de modo permanente e sem comprometer o acesso a outras necessidades essenciais, com base em práticas alimentares saudáveis, contribuindo assim para uma existência digna em um contexto de desenvolvimento integral da pessoa humana. (Valente, F.L.S. Do combate à fome à segurança alimentar e nutricional: o direito à alimentação adequada. Revista de Nutrição PUCCAMP, v.10, n.1, p.25, jan./jun. 1997)
} 
determinadas regiões e períodos. Registros da FAO (2000) reconhecem os fatores que têm afetado mais severamente a segurança alimentar da população, os quais estão diretamente ligados às condições físicas e econômicas da própria vida urbana. Políticas de ajustamento econômico têm reduzido as oportunidades de emprego, retirando os subsídios para produtos agrícolas e conduzindo também à desvalorização do câmbio.

Valente (1997) refere que a incapacidade de acesso aos alimentos, associado ao poder de compra de uma população, é o principal fator determinante da insegurança alimentar. $O$ autor destaca que a sociedade brasileira tem convivido nos últimos anos com a coexistência de doenças associadas à pobreza e à exclusão social e também com aquelas associadas a hábitos alimentares inadequados, que atingem todas as parcelas da população.

Hoffmann (1994) relata que o problema da fome no Brasil, não se deve a pouca disponibilidade de alimentos, mas sim à situação de pobreza em que vive grande parcela da população.

De acordo com Angelis (2000), os hábitos alimentares de uma população dependem principalmente do que a população aprecia consumir, das condições de acesso aos alimentos e das condições de produção do mercado.

O consumo alimentar é um tema muito complexo no qual se deve analisar o conjunto de fatores que determinam as mudanças e a diversificação dos hábitos alimentares, bem como o estudo sobre as relações que se estabelecem entre os vários elos que compõem a cadeia alimentar (produtores agrícolas, industriais, comerciantes e consumidores). Além disto, existe o papel do estado que tem dificuldades para estabelecer uma diretriz, envolvendo o sistema produtivo e a saúde pública (Oliveira \& Thébaud-Mony, 1997).

Silva (1991) faz uma reflexão sobre a produção e o consumo de alimentos no Brasil, relatando que a política adotada em meados dos anos 90 favoreceu predominantemente a agricultura de exportação, com desestímulo para a produção de gêneros básicos de consumo. Ocorreu o aumento nos juros e redução no subsídio aos produtores. Ainda de acordo com o referido autor, 
pesquisas sobre o consumo alimentar realizadas na metade da década de 90 confirmavam que ocorria uma insuficiência nutricional quantitativa em grupos populacionais de baixa renda, ainda que a alimentação dessas populações consumisse $51 \%$ dos recursos das famílias, com menores rendimentos (inferior à dois salários mínimos).

Neves, Chaddad e Lazzarini (2000) citam que em 1998, a porcentagem média da renda dos brasileiros gasta com alimentação esteve ao redor de $40 \%$. Esse valor é mais do que o dobro quando comparado com os dados dos países da União Européia (UE) e dos Estados Unidos. Por outro lado, existem segmentos no Brasil com percentual de renda destinado à alimentação, inferior a 15\% de seus rendimentos totais (grupo considerado mais rico).

Galeazzi et al. (1997) afirmam que o Brasil apresentou mudanças drásticas em seu perfil socioeconômico e demográfico nos anos que se seguiram à publicação do Estudo Nacional de Despesa Familiar - ENDEF. A urbanização acelerada, a estagnação econômica, o processo inflacionário e inúmeras políticas de ajuste econômico afetaram substancialmente o padrão alimentar da população brasileira. As pesquisas que se seguiram ao ENDEF (até hoje considerada a melhor fonte de dados, porém de custo elevado) disponibilizam, predominantemente, dados sobre o consumo de alimentos (do ponto de vista econômico) e sua relação com a renda familiar. Ou seja, não se dispõe, no País, de dados representativos do consumo real de alimentos e sim sobre a aquisição de produtos alimentícios.

Cabe mencionar que a estabilização da moeda alcançada com a implantação do Plano Real (1994), possibilitou um incremento no consumo de bens pela população brasileira, principalmente no que se refere ao consumo de alimentos, que exibiu um crescimento de 50\%. As grandes mudanças envolveram especialmente os grupos de renda mais baixa, os quais tinham, até então, seus rendimentos corroídos pela inflação, cujos índices variavam de 15 a $20 \%$ ao mês. Para os referidos grupos, o consumo limitava-se aos alimentos da "cesta básica", com limitações de acesso a uma diversidade maior de outros 
gêneros. Com a implantação do Plano Real o grupo mais pobre começa incorporar mudanças nos seus hábitos de consumo (Marques, 1998).

Dados da Pesquisa Nacional por Amostra de Domicílio - PNAD de 1995, revelam uma melhora nos indicadores econômicos no período de 1990 a 1995, onde a concentração de renda teve um decréscimo, com redução de 1,5\% do percentual retido pelos $10 \%$ mais ricos e aumento da participação dos $20 \%$ mais pobres em $0,6 \%$. O rendimento médio mensal aumentou em torno de $30 \%$ entre 1993 e 1995 (Valente, 1997).

De acordo com Silva (1998), a implantação do Plano Real trouxe uma relativa melhora na redistribuição da renda e também melhorias relacionadas ao consumo alimentar. Houve um incremento ao acesso da população, especialmente no que se refere a uma ampliação na diversificação do consumo de alimentos. Assim sendo, poderia se pensar em uma sensível melhoria na qualidade da dieta da população. Porém foi observada, por meio de pesquisas regionais, uma redução no consumo de feijão, frutas e hortaliças. Lerner (1994) identificou um aumento no consumo de embutidos, queijos e pães entre adolescentes e em famílias cujas mães trabalham fora do domicílio.

Ainda no que tange às mudanças decorrentes dos ajustes econômicos, Neves, Chaddad e Lazzarini (2000) relatam que na vigência do Plano Real o aumento de renda da população conduziu a mudanças no comportamento do consumidor de alimentos e bebidas. Tal processo causou impacto em praticamente a totalidade dos sistemas agroalimentares. As principais mudanças ocorreram no consumo de alimentos fora do domicílio, com expansão da rede de fast-food ${ }^{2}$ e no consumo de produtos de fácil preparo e cocção. Cresceu também a preocupação dos consumidores com relação ao alimento seguro, ou seja, maior parcela da população passou a manifestar preocupação com a origem dos alimentos. Também, de acordo com os referidos autores, a estrutura etária da população tem passado por profundas

\footnotetext{
${ }^{2}$ Fast-food é expressão inglesa que significa comida rápida.
} 
alterações, ou seja, tem crescido a participação dos idosos, no contingente da população.

Monteiro, Mondini e Costa (2000) registram que após a implantação do Plano Real, observou-se uma alteração no consumo alimentar da população brasileira, com maior destaque para o conteúdo energético, o qual apresentou um ligeiro incremento. Os autores relatam ainda que ocorreram mudanças no padrão da composição nutricional da dieta da população, principalmente no que se refere à adequação de nutrientes. Reconhece-se que o consumo alimentar e possíveis mudanças neste, podem causar danos para a saúde, tanto pela insuficiência como pelo excesso. Prejuízos podem ocorrer, principalmente com relação às doenças crônicas da idade adulta que cada vez mais têm acometido a população. Associada a essas doenças, entre outras causas, a alimentação parece ocupar posição central e exercer decisiva influência. O consumo elevado de colesterol e gorduras saturadas está relacionado ao risco de doença coronariana. Dietas com baixo consumo de frutas e hortaliças parecem estar correlacionadas com alto índice de câncer. A relação entre o consumo freqüente de açúcar e prevalência de cárie dental, a relação entre pressão alta e consumo de sal, o elevado consumo de bebidas alcoólicas associado com hipertensão, doenças cérebro-vasculares, hepatopatias, alguns tipos de câncer, osteoporose, entre outras, têm indicado que a mudança na composição da dieta dos brasileiros tem exercido iinfluência negativa sobre seu estado de saúde (Monteiro, Mondini e Costa, 2000).

Lerner et al. (2000) e Mattos \& Martins (2000) referem em suas pesquisas, redução da desnutrição energético-protéica e o surgimento de "novos" problemas nutricionais.

Mondini (1996) ressalta que a obesidade se configura como principal distúrbio nutricional, tanto em adultos como crianças, sendo que a região Sul do Brasil é a que mais concentra este problema, tanto no meio urbano como rural.

Batista Filho \& Rissin (2003) destacam que os efeitos dos programas ligados à área de alimentação e nutrição, tais como o Programa de Incentivo ao 
Aleitamento Materno, Programa de Suplementação Alimentar (PSA), Programa Bolsa Alimentação (PBA), Programa Nacional de Alimentação Escolar (PNAE) e Programa de Alimentação do Trabalhador (PAT), podem estar exercendo influência sobre a atual situação nutricional da população brasileira.

Com relação às carências nutricionais, destacam-se as deficiências de vitamina $A$, iodo e ferro, principalmente entre os indivíduos da Região Nordeste do Brasil. Porém, inúmeras pesquisas têm demonstrado deficiência de micronutrientes acometendo grupos populacionais de regiões mais ricas, quando comparada à Região Nordeste, a qual é considerada a região mais pobre do Brasil (Monteiro, Mondini e Costa, 2000; Millen et al., 1997; Valente, 1997; Velasquez-Melendez et al., 1997.

Cabe registrar que substanciais mudanças ocorreram mundialmente nas últimas décadas envolvendo, especialmente, os hábitos alimentares. Tal situação mostra que os fatores econômicos, sociais, nutricionais e culturais têm papel decisivo nos hábitos alimentares e, portanto, devem ser exaustivamente analisados, quando se avalia o padrão de consumo alimentar da população brasileira (Oliveira \& Thébaud-Mony,1997).

Sichieri, Castro e Moura (2003) concluem em sua pesquisa, que entre as diversas variáveis que interferem nos padrões alimentares, merecem destaque o tamanho do domicílio, aspectos econômicos, cor, estado civil e a região de residência.

No que tange ao monitoramento do consumo, acesso e estado nutricional da população, cabe lembrar que em 1974, a FAO, durante a Conferência Mundial de Alimentação recomendou que todos os países assegurassem o acesso aos alimentos para toda a população humana. Com isto, os países desenvolvidos investiram em sistemas de informações que viabilizassem o monitoramento da situação alimentar e nutricional da população (Leal \& Bittencourt, 1997).

Ainda de acordo com Leal \& Bittencourt (1997), no Brasil foram realizados vários inquéritos nutricionais com o objetivo de conhecer e 
acompanhar a magnitude dos problemas relacionados à alimentação e nutrição. O primeiro inquérito foi realizado em 1974/1975, pelo Instituto Brasileiro de Geografia e Estatística (IBGE) denominado ENDEF - Estudo Nacional de Despesa Familiar, que teve como objetivo avaliar o consumo alimentar e a estrutura de despesa familiar, bem como o estado nutricional de uma amostra representativa da população brasileira.

Em 1987/1988, o IBGE realizou uma Pesquisa de Orçamentos Familiares (POF), cujo objetivo foi conhecer os gastos com despesas familiares, o que pôde determinar, ainda que de forma indireta, o consumo de alimentos de famílias em regiões metropolitanas do Brasil.

Em 1989 foi realizada a Pesquisa Nacional sobre Saúde e Nutrição (PNSN), a qual teve como objetivo principal avaliar o estado nutricional, as condições de saúde e a estrutura socioeconômica da população brasileira.

Na década de 90, o extinto Instituto Nacional de Alimentação e Nutrição (INAN) realizou juntamente com universidades brasileiras um Estudo Multicêntrico envolvendo amostras da população de sete cidades brasileiras. 0 objetivo central do estudo foi avaliar o consumo alimentar e a atividade física de uma amostra representativa da população.

Em 1995/1996, o IBGE implementou uma nova Pesquisa de Orçamentos Familiares, adotando praticamente os mesmos moldes da pesquisa realizada em 1987/1988, com a incorporação de alguns ajustes metodológicos.

O IBGE concluiu em junho de 2004 a coleta e organização dos dados de uma nova POF. Nessa pesquisa foram obtidas informações de amostra representativa de famílias da totalidade das regiões metropolitanas, e também da zona rural. No entanto, até o momento, foram disponibilizados, pelo IBGE, apenas dados preliminares.

Cabe destacar que o conjunto de pesquisas já consolidadas, foram fundamentais para viabilizar análises visando à identificação dos problemas nutricionais da população brasileira, suas causas e conseqüências. Os dados sobre consumo alimentar que retratam mais fielmente o consumo da população 
são obtidos por meio da realização de inquéritos dietéticos, porém o seu alto custo torna a adoção deste método praticamente inviável, em nosso meio.

Rocha (1999) cita que as POF's têm entre os seus objetivos principais, a obtenção de elementos que subsidiem o estabelecimento dos Índices de Preços ao Consumidor (IPC), os quais se baseiam em estruturas de despesas observadas durante o período de um ano. Por outro lado, estas informações sobre os gastos com alimentação podem refletir, ainda que indiretamente, os hábitos da população e sua adequação nutricional.

Galeazzi et al. (1996) afirmam que os inquéritos dietéticos e as pesquisas de orçamentos familiares, embora incompletos como instrumento diagnóstico, são os únicos de que se dispõe, não só para conhecer as práticas alimentares mas também para avaliar a viabilidade de intervenções que visam mudanças nos hábitos alimentares.

Segundo Monteiro, Mondini e Costa (2000), a análise de dados fornecidos pelas POF's, por meio da realização de inquéritos domiciliares com levantamento dos gastos com alimentação e dos preços pagos pelas famílias, integrantes da amostra, permite estimar a disponibilidade individual de alimentos para cada família. Porém, como qualquer pesquisa, também reúne algumas limitações pois não considera o desperdício de alimentos, nem os alimentos que foram doados ou consumidos fora do domicílio e também não informam sobre a distribuição de alimentos entre os membros da família.

A realização da POF 1995/1996 foi de importância adicional, tendo em vista que tem possibilitado a elaboração de análises sobre o consumo e despesa com alimentação no período imediatamente posterior ao Plano Real. Tal característica permitiu obter informações mais precisas sobre consumo e sem distorções resultantes do processo inflacionário. Foi possível captar mudanças que resultaram tanto da própria estabilidade de preços como do aumento da renda real, sendo que estas mudanças tiveram impacto principalmente sobre o consumo de alimentos (Rocha, 1999) 
De acordo com Barretto, Cyrillo e Cozzolino (1998), desde a instituição da Ração Essencial, acoplada à lei do salário mínimo de 1938, inúmeras "cestas de alimentos" têm sido constituídas no Brasil. Estas cestas, invariavelmente classificadas como básicas têm como meta a racionalidade econômica de se buscar a maximização do bem estar, diante da renda disponível e dos preços vigentes. Os autores registram que algumas destas "cestas" se fundamentam em propostas provenientes das áreas de saúde pública com intuito de atender, ao menos parcialmente, as recomendações nutricionais preconizadas, minimizando assim possíveis danos à saúde.

Inúmeras pesquisas, embora envolvendo amostras menores e em distintas regiões do País, têm sido realizadas com objetivos de conhecer ou obter maior acervo de informações sobre saúde e nutrição (Fornés et al., 2000; Lerner et al., 2000; Mattos \& Martins, 2000; Millen et al., 1997; VelasquezMelendez et al., 1997).

Cabe reafirmar que diversas são as variáveis que interferem nos hábitos alimentares de uma população. Aspectos sociais, culturais e principalmente econômicos têm influenciado a ingestão inadequada de alimentos e com isto contribuído para o aumento expressivo da prevalência de várias doenças. Tais informações podem ser consideradas como argumentos suficientes para a implementação da presente pesquisa. 


\section{MATERIAL E MÉTODOS}

\subsection{Base de dados}

O presente trabalho foi realizado, adotando-se como base de dados as informações obtidas pelo IBGE (Instituto Brasileiro de Geografia e Estatística, 1998) por meio da Pesquisa de Orçamentos Familiares (POF-1995/1996). Foram selecionados, para as análises, os dados relativos à população residente nas áreas metropolitanas de Curitiba e Porto Alegre, pertencentes ao estado do Paraná e Rio Grande do Sul (integrantes da Região Sul), respectivamente.

O Quadro 1 mostra os municípios que pertencem as regiões metropolitanas de Curitiba e Porto Alegre e que integraram a amostra da POF (1995-1996). 


\begin{tabular}{|l|l|}
\hline \multicolumn{1}{|c|}{ Região metropolitana } & \multicolumn{1}{|c|}{ Municípios integrantes } \\
\hline Curitiba & $\begin{array}{l}\text { Almirante Tamandaré, Araucária, Balsa Nova, Bocaiúva do } \\
\text { Sul, Campina Grande do Sul, Campo Largo, Colombo, } \\
\text { Contenda, Curitiba, Mandirituba, Piraquara, Quatro Barras, } \\
\text { Rio Branco do Sul, São José dos Pinhais, Cerro Azul, } \\
\text { Quitandinha e Tijucas do Sul }\end{array}$ \\
\hline Porto Alegre & $\begin{array}{l}\text { Alvorada, Cachoeirinha, Campo Bom, Canoas, Dois Irmãos, } \\
\text { Eldorado do Sul, Estância Velha, Esteio, Glorinha, Gravataí, } \\
\text { Guaíba, Ivoti, Nova Hartz, Novo Hamburgo, Parobé, Portão, } \\
\text { Porto Alegre, São Leopoldo, Sapiranga, Sapucaia do Sul, } \\
\text { Triunfo, Viamão }\end{array}$ \\
\hline
\end{tabular}

Quadro 1 - Municípios integrantes das regiões metropolitanas de Curitiba e Porto Alegre

Fonte: IBGE (1998)

As características econômicas e demográficas da população que integra a presente pesquisa, são apresentadas no Quadro 2. 


\begin{tabular}{|c|c|c|c|c|c|}
\hline $\begin{array}{c}\text { Região } \\
\text { Metropolitana }\end{array}$ & $\begin{array}{c}\text { Estrato de } \\
\text { Recebimento } \\
\text { (em salários mínimos) }\end{array}$ & Limite & $\begin{array}{c}\text { Recebimento } \\
\text { Total }\end{array}$ & \begin{tabular}{|c|} 
Número de \\
Famílias
\end{tabular} & $\begin{array}{c}\text { Número de } \\
\text { Pessoas }\end{array}$ \\
\hline Curitiba & Até 2 & 0 & 150,37 & 31.064 & 79.346 \\
\hline Porto Alegre & Até 2 & 0 & 150,84 & 69.496 & 185.568 \\
\hline Curitiba & Mais de 2 a 3 & 224 & 285,41 & 43.229 & 128.074 \\
\hline Porto Alegre & Mais de 2 a 3 & 224 & 286,60 & 67.292 & 196.402 \\
\hline Curitiba & Mais de 3 a 5 & 336 & 446,23 & 81.689 & 289.513 \\
\hline Porto Alegre & Mais de 3 a 5 & 336 & 452,02 & 140.059 & 455.712 \\
\hline Curitiba & Mais de 5 a 6 & 560 & 615,95 & 45.406 & 161.756 \\
\hline Porto Alegre & Mais de 5 a 6 & 560 & 626,41 & 65.131 & 224.848 \\
\hline Curitiba & Mais de 6 a 8 & 672 & 781,84 & 75.243 & 296.149 \\
\hline Porto Alegre & Mais de 6 a 8 & 672 & 776,62 & 101.102 & 337.096 \\
\hline Curitiba & Mais de 8 a 10 & 896 & $1.009,34$ & 58.598 & 228.546 \\
\hline Porto Alegre & Mais de 8 a 10 & 896 & $1.005,00$ & 80.658 & 301.121 \\
\hline Curitiba & Mais de 10 a 15 & 1120 & $1.390,62$ & 89.243 & 328.003 \\
\hline Porto Alegre & Mais de 10 a 15 & 1120 & $1.374,97$ & 140.858 & 528.036 \\
\hline Curitiba & Mais de 15 a 20 & 1680 & $1.977,72$ & 51.913 & 212.451 \\
\hline Porto Alegre & Mais de 15 a 20 & 1680 & $1.972,78$ & 67.916 & 234.814 \\
\hline Curitiba & Mais de 20 a 30 & 2240 & $2.796,15$ & 46.283 & 189.663 \\
\hline Porto Alegre & Mais de 20 a 30 & 2240 & $2.733,45$ & 70.788 & 233.451 \\
\hline Curitiba & Mais de 30 & 3360 & $6.541,92$ & 79.078 & 298.924 \\
\hline Porto Alegre & Mais de 30 & 3360 & $6.946,30$ & 111.146 & 377.273 \\
\hline
\end{tabular}

Quadro 2 - Características econômicas e demográficas das famílias pertencentes às Regiões Metropolitanas de Curitiba e Porto Alegre

Fonte: IBGE (1998)

Os dados da POF 1995/1996 foram coletados entre $1^{\circ}$ - de outubro de 1995 e 30 de setembro de 1996, período que contempla todas as épocas do ano e permite que os resultados reflitam um padrão médio anual e também as variações dos gastos e recebimentos das famílias (IBGE, 1998). 
Os resultados relativos ao consumo alimentar domiciliar foram obtidos de forma direta, por meio do registro das quantidades físicas de alimentos e bebidas adquiridos para consumo. Tal opção decorre do entendimento de que todo volume adquirido representa o consumo, uma vez que ao longo de um ano de pesquisa, parte das famílias pesquisadas forma um estoque alimentar, e outra parcela consome os produtos estocados, promovendo assim um equilíbrio entre despesa e consumo de alimentos.

De acordo com o IBGE (1998) a seleção das amostras foi feita com base no Censo Demográfico de 1991, considerados os setores urbanos e favelas, das capitais e regiões metropolitanas e que tivessem pelo menos dois domicílios particulares permanentes. Posteriormente foi feito um cadastramento de todos os domicílios pertencentes aos referidos setores. Para compensar as perdas provenientes de entrevistas não realizadas, o número de domicílios selecionados teve um acréscimo de 30\%. No quadro apresentado a seguir, é mostrado o número de domicílios "esperados", "selecionados" e "entrevistados"3, segundo as áreas da pesquisa. O número de domicílios "selecionados" corresponde ao total previsto na seleção da amostra; domicílios "esperados" corresponde à hipótese de dez entrevistas realizadas, por setor, durante o dimensionamento da amostra; e domicílios entrevistados, a amostra que realmente fez parte da pesquisa.

\footnotetext{
${ }^{3}$ A identificação domicílios “esperados”, "selecionados” e “entrevistados” é adotada pelo IBGE.
} 


\begin{tabular}{|c|c|c|c|}
\hline Área da pesquisa & $\begin{array}{l}\text { No de domicílios } \\
\text { "esperados" }\end{array}$ & $\begin{array}{l}\mathrm{N}^{\circ} \text { de domicílios } \\
\text { "selecionados" }\end{array}$ & $\begin{array}{l}\mathrm{N}^{0} \text { de domicílios } \\
\text { "entrevistados" }\end{array}$ \\
\hline Curitiba & 1050 & 1409 & 1095 \\
\hline Porto Alegre & 1060 & 1424 & 1223 \\
\hline Belém & 1280 & 1699 & 1415 \\
\hline Fortaleza & 1750 & 2398 & 1982 \\
\hline Recife & 1740 & 2349 & 1891 \\
\hline Salvador & 1420 & 1983 & 1488 \\
\hline Belo Horizonte & 1360 & 1840 & 1548 \\
\hline Rio de Janeiro & 1440 & 2001 & 1623 \\
\hline São Paulo & 1240 & 1734 & 1352 \\
\hline Brasília-DF & 880 & 1177 & 880 \\
\hline Goiânia & 1340 & 1802 & 1517 \\
\hline
\end{tabular}

Quadro 3 - Domicílios "esperados, selecionados e entrevistados" segundo as áreas de pesquisa

Fonte: IBGE (1998)

Segundo o IBGE (1998), para a Pesquisa de Orçamentos Familiares (POF-1995/1996) foram utilizados cinco modelos de registros para a coleta de informações, cujos títulos são apresentados no APÊNDICE 1.

O processo de obtenção das informações da POF foi dividido em 52 períodos semanais. As informações foram obtidas diretamente nos domicílios selecionados, por meio de entrevistas junto aos moradores, durante um período de sete dias subseqüentes.

O consumo de alimentos per capita foi obtido, utilizando-se a Caderneta de Despesa Coletiva - POF 3 (APÊNDICE 1), onde foram registrados, diariamente e durante sete dias consecutivos, a descrição detalhada de cada produto adquirido, o valor pago, a unidade de medida, o local da compra e a quantidade indicada em gramas ou mililitros.

Ainda de acordo com o IBGE (1998), a partir dos resultados relativos às quantidades de produtos alimentares adquiridos pelas famílias (para o consumo domiciliar), o consumo per capita foi obtido, distribuindo estas quantidades pela população em cada classe de recebimento: até 2 salários mínimos (SM); mais de 2 a 3 SM; mais de 3 a 5 SM; mais de 5 a 6 SM; mais de 6 a 8 SM; mais de 8 a 10 SM; mais de 10 a 15 SM; mais de 15 a 20 SM; mais de 20 a 30 SM; e mais 
de 30 SM. Como resultado, obteve-se o consumo alimentar per capita desta população, para o período de um ano. Cabe ressaltar que alguns produtos foram agregados em grupos e subgrupos, de acordo com as características morfológicas dos mesmos e da forma como são comercializados.

Julgou-se importante apresentar, neste trabalho, os dados relativos às despesas das famílias integrantes da amostra da POF, com destaque para as Regiões Metropolitanas de Curitiba e Porto Alegre (Região Sul), no que tange à alimentação no domicílio e fora deste, conforme quadro mostrado a seguir (Quadro 4).

\begin{tabular}{|l|c|c|c|c|c|}
\hline \multirow{3}{*}{$\begin{array}{c}\text { Região } \\
\text { Metropolitana }\end{array}$} & \multirow{2}{*}{$\begin{array}{c}\text { Total dos gastos } \\
\text { (em Reais) }\end{array}$} & \multicolumn{4}{|c|}{$\begin{array}{c}\text { Valor em reais da despesa mensal familiar } \\
\text { de acordo com o local }\end{array}$} \\
\cline { 3 - 6 } & & \multicolumn{3}{|c|}{ No domicílio } & \multicolumn{2}{c|}{ Fora do domicílio } \\
\cline { 3 - 6 } & & Valor (R\$) & $\begin{array}{c}\text { Participação } \\
\text { relativa }\end{array}$ & Valor (R\$) & $\begin{array}{c}\text { Participação } \\
\text { relativa }\end{array}$ \\
\hline Curitiba & 241,60 & 188,81 & 78,15 & 52,79 & 21,85 \\
\hline Porto Alegre & 231,99 & 174,63 & 75,27 & 57,36 & 24,72 \\
\hline
\end{tabular}

Quadro 4 - Valor e participação relativa da despesa média mensal familiar com alimentação no domicílio e fora do domicílio

Fonte: IBGE (1998)

Cabe ressaltar que a POF, ainda que não tenha sido proposta com o objetivo de analisar a situação nutricional da população, permite estabelecer relações entre a despesa feita com alimentos e o consumo indireto dos mesmos. Rocha (1999) refere que a despesa monetária não corresponde necessariamente ao consumo, mas por outro lado, o gasto monetário é parcela expressiva do consumo alimentar em áreas urbanas.

Como recomendado por Machado (2003), no contexto do presente trabalho, as expressões "consumo alimentar" e "consumo de alimentos" são definidas como equivalentes ao consumo nutricional do alimento, ou seja, 
ingestão alimentar; enquanto que o consumo de alimentos no sentido estritamente econômico é designado como "aquisição de alimentos", "compra de alimentos" ou "disponibilidade de alimentos". Desse modo, o termo "disponibilidade de alimentos" não é equivalente à oferta de alimentos, conforme poderia ser interpretado sob o ponto de vista econômico, pois representa a quantidade de alimentos à disposição dos indivíduos, integrantes do estudo, após a aquisição.

\subsection{Análise dos dados}

De posse dos dados (tabulações especiais, em meio magnético), disponibilizados pelo IBGE, por meio da POF - 1995/1996 (IBGE, 1998), relativos ao consumo alimentar per capita anual dos integrantes das famílias pesquisadas, foram construídas planilhas de consumo per capita diário. O consumo alimentar domiciliar per capita (quilogramas) foi dividido por 365 dias e o valor obtido foi multiplicado por 1000. Para esta atividade, foi utilizado o software Microsoft Excel (versão 6.0, 1997).

A análise nutricional foi realizada com base no conteúdo de energia, de macronutrientes selecionados (carboidratos, proteínas e lipídeos), fibras, colesterol e micronutrientes (vitaminas e minerais) para as famílias das regiões metropolitanas de Curitiba e Porto Alegre, pertencentes à totalidade dos estratos de renda. Utilizou-se para a viabilização dos cálculos, o software Virtual Nutri (Philippi et al., 1996) desenvolvido por pesquisadores da Faculdade de Saúde Pública da Universidade de São Paulo. A composição nutricional dos alimentos que não constavam do banco de dados do referido software, foi obtida por meio de consulta em outras fontes e os dados incorporados ao arquivo. As fontes consultadas foram a Tabela de Composição Química de Alimentos do ENDEF (IBGE, 1978), a Tabela de Composição Química de Alimentos (IBGE, 1981), a Tabela de Composição Química de Alimentos 
(Franco, 1992) e a Tabela Brasileira de Composição de Alimentos (Faculdade de Ciências Farmacêuticas da USP, 2001).

Para a análise qualitativa do Valor Energético Total - VET disponível, foi adotado como referência as recomendações preconizadas pela National Academy of Sciences - NAS (2003), que considera aceitável os seguintes intervalos de participação dos macronutrientes: 45-65\% proveniente dos carboidratos, $20-35 \%$ dos lipídeos e $10-35 \%$ das proteínas. Registra-se que a NAS (2003) preconiza cerca de $2500 \mathrm{kcal}$ para indivíduo adulto saudável.

Tendo em vista a importância do atendimento das necessidades de aminoácidos, neste trabalho foi analisada também a participação da proteína, em relação a sua origem (animal ou vegetal), tendo com parâmetro a recomendação de $35 \%$ do conteúdo protéico proveniente de origem animal (Vanucchi et al., 1990).

Com relação às fibras, utilizou-se como parâmetro a recomendação média de 25g/dia, conforme proposto pelo NAS (2003). Para a análise do colesterol, o parâmetro considerado para as análises comparativas, foi o limite máximo (consumo dietético) de 300 mg/dia (2003).

Para os micronutrientes, julgou-se pertinente adotar também as recomendações da NAS (2003) preconizadas para indivíduo adulto, com idade entre 31 e 50 anos. Para efeito de comparação entre os dados obtidos no presente trabalho com os valores preconizados, optou-se por utilizar a média dos valores registrados para homens e mulheres, conforme mostrado no Quadro 5. 


\begin{tabular}{|l|c|l|c|}
\hline \multicolumn{1}{|c|}{ Vitaminas } & $\begin{array}{c}\text { Valores preconizados } \\
\text { (Médias) }\end{array}$ & \multicolumn{1}{|c|}{ Minerais } & $\begin{array}{c}\text { Valores } \\
\text { preconizados } \\
\text { (Médias) }\end{array}$ \\
\hline Vitamina A $(\mu \mathrm{g})$ & 800 & lodo $(\mu \mathrm{g})$ & 150 \\
Vitamina C $(\mathrm{mg})$ & 82,5 & Sódio $(\mathrm{g})$ & 4 \\
Vitamina B1 $(\mathrm{mg})$ & 1,1 & Cálcio $(\mathrm{mg})$ & 1000 \\
Vitamina B2 $(\mathrm{mg})$ & 1,2 & Magnésio $(\mathrm{mg})$ & 370 \\
Vitamina B6 $(\mathrm{mg})$ & 1,3 & Zinco $(\mathrm{mg})$ & 9,5 \\
Vitamina B12 $(\mathrm{mg})$ & 2,4 & Manganês $(\mathrm{mg})$ & 2,0 \\
Vitamina D $(\mu \mathrm{g})$ & 5 & Potássio $(\mathrm{g})$ & 2 \\
Niacina $(\mathrm{mg})$ & 15 & Fósforo $(\mathrm{mg})$ & 700 \\
Folacina $(\mu \mathrm{g})$ & 400 & Ferro $(\mathrm{mg})$ & 13 \\
Ac. pantot. $(\mathrm{mg})$ & 5 & Cobre $(\mathrm{mg})$ & 9 \\
Vitamina $E(\mathrm{mg})$ & 15 & Selênio $(\mu \mathrm{g})$ & 55 \\
& & & \\
\hline
\end{tabular}

Quadro 5 - Recomendações (média) de ingestão de vitaminas e minerais Fonte: NAS (2003)

Elaborou-se também análise da participação relativa de alimentos in natura e industrializados ${ }^{4}$ no VET disponível nos domicílios das famílias residentes nas duas regiões metropolitanas selecionadas. Os alimentos considerados in natura, no presente trabalho são as frutas, hortaliças, arroz, leguminosas, oleaginosas, carnes não processadas, ovos e leite fresco.

Outra análise implementada refere-se à participação relativa dos grupos alimentares no Valor Energético Total (VET) diário das famílias, de acordo com o estrato de renda a que pertencem. Para facilitar a interpretação dos dados, inicialmente foram distinguidos os alimentos conforme critérios de semelhança quanto à composição nutricional entre os mesmos. Em seguida, foi somado o valor nutricional de cada grupo alimentar e calculado a sua participação percentual em relação ao VET total diário das famílias, descriminadas por estrato de renda familiar. No total foram selecionados 17 grupos alimentares, a saber: cereais e derivados; raízes, tubérculos e derivados; carnes e embutidos; leguminosas; leite e derivados; ovos; legumes e verduras (hortaliças); frutas;

${ }^{4}$ Considerou-se alimento industrializado o produto obtido de processamento de um ou mais tipos de alimentos, adicionado ou não de outras substâncias permitidas, por meio de processos tecnológicos adequados (AQUINO, R.C de; PHILIPPI, S.T. Revista de Saúde Pública, v.36, n.6, p.655-660, dez. 2002) 
açúcares e doces; óleos e gorduras vegetais; banha, toucinho, maionese e creme de leite; oleaginosas; refrigerantes; bebidas não alcoólicas; bebidas alcoólicas; preparações prontas; e condimentos. 


\section{RESULTADOS E DISCUSSÃo}

\subsection{Análise de energia e macronutrientes}

A disponibilidade (nos domicílios) de energia e a participação (relativa) de macronutrientes (proteínas, carboidratos e lipídios) no Valor Energético Total - VET das famílias das Regiões Metropolitanas - RM de Curitiba e Porto Alegre, são mostradas na Tabela 1. 
Tabela 1. Disponibilidade de energia e participação dos macronutrientes (proteínas, carboidratos e lipídios) nos domicílios das Regiões Metropolitanas de Curitiba e Porto Alegre, de acordo com o recebimento familiar per capita. 1995/1996

\begin{tabular}{|c|c|c|c|c|c|c|c|c|}
\hline \multirow{2}{*}{$\begin{array}{c}\text { Região } \\
\text { Metropolitan } \\
\text { a } \\
\end{array}$} & \multirow{2}{*}{ Estrato de Recebimento } & \multirow{2}{*}{$\begin{array}{c}\text { Energia } \\
\text { (kcal) }\end{array}$} & \multicolumn{2}{|c|}{ Proteína } & \multicolumn{2}{|c|}{ Carboidratos } & \multicolumn{2}{|c|}{ Lipídios } \\
\hline & & & (g) & $(\%)$ & (g) & $(\%)$ & (g) & $(\%)$ \\
\hline Curitiba & Até 2 & 2044,2 & 61,7 & 12,1 & 332,5 & 65,1 & 52,2 & 23,0 \\
\hline Porto Alegre & Até 2 & 1227,7 & 45,4 & 14,8 & 185,0 & 60,3 & 35,0 & 25,6 \\
\hline Curitiba & Mais de 2 a 3 & 1899,3 & 51,4 & 10,8 & 290,5 & 61,2 & 61,6 & 29,2 \\
\hline Porto Alegre & Mais de 2 a 3 & 1754,8 & 58,9 & 13,4 & 259,0 & 59,0 & 55,4 & 28,4 \\
\hline Curitiba & Maisde 3 a 5 & 1703,4 & 52,7 & 12,4 & 259,0 & 60,8 & 52,5 & 27,7 \\
\hline Porto Alegre & Mais de 3 a 5 & 1692,0 & 58,6 & 13,9 & 258,8 & 61,2 & 48,8 & 26,0 \\
\hline Curitiba & Mais de 5 a 6 & 2095,9 & 60,9 & 11,6 & 309,4 & 59,0 & 70,6 & 30,3 \\
\hline Porto Alegre & Mais de 5 a 6 & 1732,5 & 47,0 & 10,8 & 285,7 & 66,0 & 45,5 & 23,6 \\
\hline Curitiba & Mais de 6 a 8 & 1970,2 & 60,5 & 12,3 & 297,6 & 60,4 & 61,8 & 28,2 \\
\hline Porto Alegre & Mais de 6 a 8 & 1533,6 & 56,3 & 14,7 & 229,2 & 59,8 & 44,6 & 26,1 \\
\hline Curitiba & Mais de 8 a 10 & 1767,7 & 59,9 & 13,6 & 243,6 & 55,1 & 63,2 & 32,2 \\
\hline Porto Alegre & Mais de 8 a 10 & 1482,4 & 55,9 & 15,1 & 210,0 & 56,7 & 47,4 & 28,8 \\
\hline Curitiba & Mais de 10 a 15 & 2056,7 & 69,8 & 13,6 & 284,8 & 55,4 & 72,7 & 31,8 \\
\hline Porto Alegre & Mais de 10 a 15 & 1910,6 & 70,2 & 14,7 & 252,1 & 52,8 & 69,3 & 32,6 \\
\hline Curitiba & Mais de 15 a 20 & 2248,0 & 69,0 & 12,3 & 319,3 & 56,8 & 80,0 & 32,0 \\
\hline Porto Alegre & Mais de 15 a 20 & 1990,0 & 72,7 & 14,6 & 278,0 & 55,9 & 67,6 & 30,6 \\
\hline Curitiba & Mais de 20 a 30 & 2172,6 & 74,0 & 13,6 & 288,9 & 53,2 & 78,9 & 32,7 \\
\hline Porto Alegre & Mais de 20 a 30 & 1559,9 & 65,2 & 16,7 & 209,5 & 53,7 & 51,3 & 29,6 \\
\hline Curitiba & Mais de 30 & 2515,9 & 89,8 & 14,3 & 351,0 & 55,8 & 85,1 & 30,4 \\
\hline Porto Alegre & Mais de 30 & 2007,7 & 74,8 & 14,9 & 272,9 & 54,4 & 69,0 & 30,9 \\
\hline
\end{tabular}

Fonte: Bleil (2004) baseado em IBGE (1998) 
Observa-se que somente as famílias pertencentes ao estrato de maior renda (acima de 30 SM na RM de Curitiba) dispõem de energia que praticamente alcança o valor preconizado para um adulto. Os grupos pertencentes aos demais estratos de renda nas duas RM, se beneficiam de conteúdo inferior. Os dados relativos às famílias mais pobres (renda até $2 \mathrm{SM}$ )

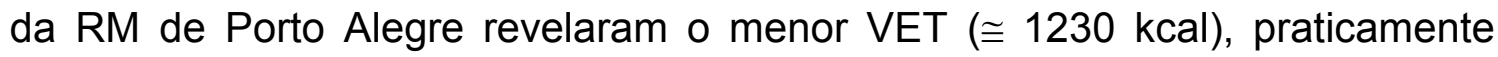
$50 \%$ do valor verificado para o grupo mais rico (acima de $30 \mathrm{SM}$ ) da mesma região metropolitana. Vale relembrar que nesta pesquisa não foi analisado o consumo alimentar fora do domicílio e, portanto, é possível que o conteúdo total médio de energia disponível para os indivíduos esteja subestimado.

Com relação aos dados observados para a RM de Curitiba, verifica-se a sua superioridade e, se ainda for considerado o consumo fora do domicílio, pode-se inferir que o conteúdo de energia se aproxima do recomendado para a população adulta.

Ao considerar a alimentação fora do domicílio, cabe registrar que Veloso \& Santana (2002) constataram uma relação positiva entre o aumento de peso dos beneficiários do Programa de Alimentação do Trabalhador (PAT) no Brasil, pertencentes aos estratos de menor renda. Esses resultados sugerem que, possivelmente o VET diário dos indivíduos, especialmente quando se considera a parcela de adultos moradores das regiões metropolitanas estudadas, seja superior ao preconizado.

Também Burlandy \& Anjos (2001) relataram um quadro de sobrepeso na população do sudeste do Brasil, no período de 1996/1997, principalmente entre os indivíduos que recebiam cesta básica/vale refeição, quando comparados ao grupo que não recebia tal benefício. Embora os dados sejam relativos à região Sudeste, sabe-se que as RM's de Curitiba e Porto Alegre também registram ampla cobertura de programas do gênero.

Quando se compara o resultado do presente trabalho com a RM de São Paulo (Faganello, 2002), observa-se que as RM de Curitiba e Porto Alegre apresentam em média maior disponibilidade energética. Em sua pesquisa, 
Faganello (2002) refere uma maior disponibilidade energética nos domicílios da RM de Recife quando comparado com a RM de São Paulo. O autor salienta ainda que este resultado causou relativa surpresa, uma vez que se esperava observar maior disponibilidade energética nos domicílios da região sudeste.

Marchioni \& Zacarelli (2002) citam que o estudo do ENDEF realizado pelo IBGE em 1974/75, indicava que o grande problema alimentar na época da pesquisa, era basicamente de caráter quantitativo e que se fossem atendidas as necessidades energéticas, também as de nutrientes seriam satisfeitas. Porém, passados cerca de trinta anos, vários problemas nutricionais permanecem, além do surgimento dos novos que acometeram a população brasileira. Contudo, o problema não está especificamente relacionado à suficiência dos macronutrientes, mas especialmente no tocante aos micronutrientes.

Existe uma tendência de que, conforme ocorre o aumento da renda, as famílias provêem uma maior quantidade de energia com alimentação fora do domicílio. Silveira et al. (2002) estimam que para a população de São Paulo, na faixa de renda acima de $30 \mathrm{SM}$ (salários mínimos) mensais, quase a metade da disponibilidade de energia per capita seja obtida por meio de refeições fora do domicílio. Na faixa de renda de até $2 \mathrm{SM}$, a participação da alimentação fora de casa corresponde a aproximadamente $21 \%$ de energia disponível. Ainda de acordo com os referidos autores, os custos dos produtos oriundos da cesta de alimentos do CEPAL para a RM de Porto Alegre, apontam para uma situação em que as famílias apresentam déficits de energia, especialmente os grupos de recebimento não muito baixos. Isto evidencia que somente a garantia da renda para a compra da quantidade recomendada de um conjunto de alimentos, não é suficiente para assegurar condição nutricional saudável. Note-se que as famílias mais pobres, também são expostas a propagandas que reforçam a tendência de adquirir produtos mais caros.

Barros (2000) registra em sua pesquisa, que no que se refere às famílias mais pobres, a inclusão dessas, como beneficiárias do programa de renda 
mínima no município de Jaboticabal (SP), privilegiou a diversificação dos gastos com inclusão de novos itens e não propriamente um aumento no consumo de alimentos. Isto pode não refletir em melhoria do estado nutricional da população atendida por este tipo de programa.

Quanto aos macronutrientes, o carboidrato, conforme se espera, é o nutriente que fornece o maior conteúdo de energia para a dieta. Na RM de Curitiba, quando são consideradas as famílias integrantes do estrato de renda de mais de 20 a $30 \mathrm{SM}$, a participação deste nutriente se revelou em torno de $53 \%$ e no estrato de até 2 SM ocorreu a maior participação (relativa), ou seja, $65 \%$. Este resultado confirma a maior participação de alimentos provenientes de origem vegetal (com predomínio de carboidratos) na dieta da população das camadas mais pobres. Esses alimentos possuem freqüentemente um preço inferior, quando comparados aos valores dos produtos de origem animal. Por outro lado, na RM de Porto Alegre, a menor participação de carboidratos foi observada para as famílias do estrato de renda de 10 a 15 SM (53\%) e a maior (66\%) foi verificada no estrato de rendimento entre 5 e 6 SM.

Faganello (2002), ao analisar os dados da POF 1995/1996, disponíveis para as RM de São Paulo e Recife encontrou resultados semelhantes, ou seja, a participação dos carboidratos no VET se revelou adequada quando se considera o intervalo de 45 e $65 \%$.

Mondini \& Monteiro (2000), analisando a participação relativa de carboidratos no consumo energético total em RM brasileiras, em três períodos 1962, 1975 e 1988, encontraram resultados similares (em média, no Brasil, a participação dos carboidratos foi de 62,1\% em 1962, de 61,2\% em 1975 e de $57,4 \%$ em 1988).

É necessário ressaltar a importância assumida pelos carboidratos no organismo humano, com especial destaque para o seu uso como "combustível" para o sistema nervoso central, fonte de energia, metabolismo normal dos lipídios, síntese de vitaminas e como precursores de componentes estruturais da célula (Tirapegui, 2000). 
Por outro lado, o excesso de carboidratos na alimentação, principalmente os classificados como simples, pode aumentar o risco para obesidade, diabetes e doenças cardiovasculares (Rosado \& Monteiro, 2001).

Com relação aos lipídios, existe também uma tendência, conforme se eleva a renda, de ocorrer crescimento na disponibilidade destes para as famílias. Porém a participação atende aos padrões recomendados (25 a 35\% do VET). A RM de Curitiba apresentou uma menor participação (23\%) deste nutriente no VET das famílias pertencentes ao estrato de renda de até $2 \mathrm{SM}$ e a maior (33\%) participação foi observada entre as famílias pertencentes ao estrato que envolve o intervalo de mais de 20 a 30 SM. Por outro lado, na RM de Porto Alegre, foi no estrato de renda entre 5 a 6 SM que o VET revelou a menor (24\%) participação de lipídios, sendo que no estrato de renda entre 10 e 15 SM, ocorreu a maior (33\%) participação.

Faganello (2002) destaca também que a renda exerce influência positiva na disponibilidade lipídica das famílias residentes nas regiões metropolitanas de Recife e São Paulo.

Silva (2000), em pesquisa realizada com adolescentes concluiu que tanto a participação de proteínas como os lipídios, encontrava-se acima dos valores recomendados e a participação dos carboidratos, inferior à preconizada. Recomenda-se grande atenção para a necessidade de adotar procedimentos de intervenção que visem a melhoria do quadro nutricional da população, uma vez que o elevado consumo de lipídios tem estreita relação com doenças crônico-degenerativas.

É importante frisar que o aumento na proporção de lipídios pode acarretar em um incremento energético da dieta (Mondini \& Monteiro, 2000).

Halpern (1996) cita que a importante mudança observada nos padrões alimentares é apontada como responsável pela redução do consumo de alimentos fontes de carboidratos e como conseqüência, um aumento significativo da participação das gorduras. 
Fornés et al. (2000) também relataram que os hábitos alimentares têm contribuído substancialmente para aumentar os níveis de lipídios sangüíneos e com isto os riscos de doenças cardiovasculares.

Cabe mencionar que de acordo com dados da Secretaria de Saúde do Estado do Rio Grande do Sul (Rio Grande do Sul, 2001), a principal causa de morte no estado em 1999, foi por doenças do aparelho circulatório (33\%).

Com relação às proteínas, para as famílias pobres (2 a 3 SM) da RM de Curitiba, foi verificada a menor participação $(11 \%)$ no VET e a maior $(14 \%)$, foi observada no estrato de renda mais elevado (> $30 \mathrm{SM}$ ). Na RM de Porto Alegre, a menor (11\%) participação protéica ocorreu no estrato de renda de mais de 5 a 6 SM. Inversamente, a maior porcentagem (17\%) foi verificada para o grupo pertencente ao estrato de renda entre 20 e 30 SM.

Estes dados parecem confirmar a cultura alimentar da população do Rio Grande do Sul, cujo consumo elevado de carnes, pode ter contribuído para a maior participação de proteína nestas famílias (Von Der Heyde et al., 2002).

Faganello (2002) ao analisar, com base nos dados da POF 1995/1996, a disponibilidade de proteína para as famílias das regiões metropolitanas de Recife e São Paulo, em três estratos de renda (até 2 SM, entre 6 à 8 SM e mais que $30 \mathrm{SM}$ ) verificou que, com exceção das faixas de renda abaixo de $2 \mathrm{SM}$ $(38,8 \mathrm{~g})$ e entre 6 e $8 \mathrm{SM}(55,6 \mathrm{~g})$ na RM de São Paulo e até $2 \mathrm{SM}(43,2 \mathrm{~g})$ na RM de Recife, os outros valores superam a recomendação.

Cervatto et al. (1997), em um estudo conduzido no município de Cotia$\mathrm{SP}$, envolvendo indivíduos com idade entre 20 e 88 anos, revelaram que a contribuição média das proteínas foi de $15 \%$, resultado considerado em conformidade com os padrões recomendados $(10-35 \%)$.

O Estudo Multicêntrico, realizado entre 1996 e 1997, tendo como amostra a população de cinco capitais brasileiras, revelou que a adequação percentual de proteínas disponível nos domicílios foi superior ao recomendado, em praticamente a totalidade dos grupamentos de renda. Somente em Goiânia e Ouro Preto, a adequação protéica foi menor que o recomendado, quando se 
considerou a menor faixa de renda salarial (até meio salário mínimo). No caso das famílias de Goiânia, foi alcançado 95\% e Ouro Preto, 89\% (Galeazzi, Domene e Sichieri, 1997).

No presente trabalho, a participação de proteínas mostra uma relação direta com a renda, ou seja, quanto maior o rendimento, maior a disponibilidade de fontes protéicas, no âmbito dos domicílios. De acordo com Oliveira \& Marchini (1998), aproximadamente $40 \%$ do acesso à fonte protéica tem relação com o poder aquisitivo da população, ou seja, quanto menor a renda, menor a disponibilidade de alimentos protéicos.

Oliveira \& Thébaud-Mony (1998) em uma pesquisa conduzida no município de São Paulo observaram que, conforme a renda aumenta, ocorre uma redução nas despesas com alimentação e uma maior diversidade de alimentos na composição das refeições.

Segundo Menezes et al. (2002), é esperado que, em decorrência do processo de desenvolvimento econômico e social, ocorra uma redução da participação dos gastos com alimentação, no total dos recursos orçamentários das famílias. Porém, para famílias de menor renda, o dispêndio monetário com alimentação ainda é o maior componente do orçamento familiar.

Mondini \& Monteiro (1994), analisando a participação relativa de macronutrientes, nas regiões metropolitanas brasileiras, em três períodos (1962, 1975 e 1988), observaram uma tendência crescente com relação ao consumo de proteínas de origem animal nas regiões nordeste e sudeste.

Parece que o consumo de proteínas pela população brasileira apresentase adequado, e que a prevalência da desnutrição está diminuindo, embora existam algumas regiões que exibem índices preocupantes (Domene et al., 1999).

Monteiro, Mondini e Costa (2000) analisando os dados das POF's de 1988 e 1996, revelam que no Centro-Sul do Brasil ocorreu uma substituição de lipídeos por proteínas, onde a participação relativa no VET disponível deste nutriente passou de 13,3\% em 1988 para 14,6\% em 1996. Estes mesmos 
autores registram que o consumo alimentar da população brasileira passava, no final da década de 90 , por um momento de transição nutricional ${ }^{5}$, caracterizado entre outros aspectos, pelo incremento da oferta de produtos de origem animal (carnes, leite e derivados).

Neves (1997) encontrou dados que revelaram um crescimento surpreendente no consumo de proteínas, especialmente de carne e leite e derivados. Em relação à carne, o consumo passou de $54 \mathrm{~kg} / \mathrm{ano} / \mathrm{habitante}$ em 1994, para 60 kg em 1995 e 64 kg em 1996.

É importante salientar que existe uma forte relação entre consumo de alimentos de origem animal, tais como carnes, leite e derivados e ovos, fontes estas expressivas de proteínas, com concentração elevada dos níveis séricos de lipoproteínas (Fornés et al., 2000).

Assim, é importante que a fonte protéica da dieta seja suprida com parcelas de proteína de origem animal e vegetal, em proporções de $35 \%$ e $65 \%$, respectivamente, a fim de satisfazer as necessidades de aminoácidos essenciais e por outro lado não comprometer os níveis plasmáticos de lipoproteínas (Vanucchi et al., 1990).

Tendo em vista a importância da identificação da origem da proteína, julgou-se pertinente a inclusão deste tipo de análise na presente pesquisa. A Tabela 2 mostra a participação relativa de proteínas, conforme a sua origem (animal ou vegetal).

${ }^{5}$ De acordo com Marchioni e Zacarelli (2002), transição nutricional é a tendência de redução dos índices de desnutrição e aumento nos índices de obesidade. (MARCHIONI, D.M.L.; ZACARELLI, E.M. Transição nutricional. Revista Higiene Alimentar, v.16, n.96, p.16-22, maio 2002) 
Tabela 2. Participação relativa (\%) de proteínas, nos domicílios de Curitiba e Porto Alegre, de acordo com a origem (animal e vegetal) e estratos de recebimento familiar. 1995/1996

\begin{tabular}{|c|c|c|c|c|c|c|c|c|c|c|}
\hline $\begin{array}{c}\text { Região } \\
\text { Metropolitana }\end{array}$ & \multicolumn{10}{|c|}{ Estratos de Recebimento (em salários mínimos) } \\
\hline $\begin{array}{c}\text { Origem da } \\
\text { Proteína }\end{array}$ & Até 2 & $\begin{array}{c}\text { Mais de } \\
2 \text { a } 3\end{array}$ & $\begin{array}{c}\text { Mais de } \\
3 \text { a } 5\end{array}$ & $\begin{array}{c}\text { Mais de } \\
5 \text { a } 6\end{array}$ & $\begin{array}{c}\text { Mais de } \\
6 \text { a } 8\end{array}$ & $\begin{array}{c}\text { Mais de } \\
8 \text { a } 10\end{array}$ & $\begin{array}{l}\text { Mais de } \\
10 \text { a } 15\end{array}$ & $\begin{array}{l}\text { Mais de } \\
15 \text { a } 20\end{array}$ & $\begin{array}{l}\text { Mais de } \\
20 \text { a } 30\end{array}$ & $\begin{array}{l}\text { Mais } \\
\text { de } 30\end{array}$ \\
\hline \multicolumn{11}{|l|}{ Curitiba } \\
\hline Proteína Animal & 42 & 47 & 51 & 48 & 51 & 56 & 55 & 51 & 61 & 58 \\
\hline Proteína Vegetal & 58 & 53 & 49 & 52 & 49 & 44 & 45 & 49 & 39 & 42 \\
\hline \multicolumn{11}{|l|}{ Porto Alegre } \\
\hline Proteína Animal & 54 & 55 & 53 & 60 & 58 & 57 & 60 & 58 & 68 & 58 \\
\hline Proteína Vegetal & 46 & 45 & 47 & 40 & 42 & 43 & 40 & 42 & 32 & 42 \\
\hline
\end{tabular}

Fonte: Bleil (2004) baseado em IBGE (1998) 
Analisando a totalidade dos estratos de rendimentos, verifica-se que a participação de proteína de origem animal se revela, de forma sistemática, superior para as famílias da RM de Porto Alegre, mantendo-se sempre acima do percentual (35\%) recomendado. Nesta RM, no estrato de renda de mais de 20 a 30 SM ocorreu a maior (68\%) participação. Na RM de Curitiba, conforme aumenta a renda, ocorre um incremento na participação de proteína de origem animal, sendo que as famílias pertencentes ao estrato de renda entre 20 e 30 SM, apresentaram maior participação de proteína de origem animal (61\%), seguido de perto (58\%) pelo grupo de famílias com o maior rendimento (> 30 SM). A menor (42\%) participação de proteína animal foi verificada entre os mais pobres (renda de até 2 SM) da RM de Curitiba e em Porto Alegre (53\%), para as famílias com rendimentos entre 3 e 5 SM.

Conforme comentado anteriormente, de forma geral a população do Rio Grande do Sul, tem por hábito consumir quantidades apreciáveis de uma preparação baseada em carne assada no espeto, conhecida por "churrasco". Esse tradicional hábito pode ser um dos fatores que contribuíram, de forma decisiva, para a sistemática superioridade da participação da proteína animal para as famílias de todos os estratos de renda na RM de Porto Alegre, quando comparada com a RM de Curitiba.

Faganello (2002), em seu trabalho demonstrou que nas RM de Recife e São Paulo, a participação da proteína de origem animal foi superior ao recomendado em todos os estratos de renda. A menor participação da RM de Recife ocorreu no estrato de renda mais de 2 a 3 SM (50\%) e a maior (62\%) foi encontrada entre os mais ricos (mais de 30 SM). Na RM de São Paulo, foi observada a menor (49\%) participação para as famílias do estrato de renda até 2 SM e a maior (65\%) participação de proteína de origem animal, no estrato de renda entre 20 e 30 SM. Comparando os resultados obtidos pelo referido autor com os dados do presente trabalho, observa-se que famílias das RM's de Recife e Porto Alegre dispõem no domicílio de maior participação de proteína de origem animal. 
De acordo com Hoffmann (1995), o consumo do feijão teve uma redução significativa principalmente em regiões urbanizadas. Este dado pode ter uma relação com a baixa participação de fontes protéicas de origem vegetal na dieta da população em estudo, uma vez que o feijão ainda é considerado uma das melhores fontes de proteína vegetal para a alimentação da população brasileira.

Tasco (1991) ao analisar a contribuição de produtos alimentícios (entre o período de 1971/72 a 1987), também observou um incremento no consumo de proteína de origem animal em detrimento da proteína de origem vegetal (especialmente o feijão).

\subsection{Análise da participação dos grupos alimentares}

A participação relativa dos grupos alimentares é analisada, tendo como base a participação média no valor energético total (VET) diário das famílias, de cada um dos grupos formados por alimentos que reúnem características similares. É importante implementar a referida análise, visando identificar como o rendimento familiar é gasto com os diferentes alimentos que compõem a pauta alimentar de uma determinada população.

$\mathrm{Na}$ Tabela 3 foram reunidos os resultados referentes à participação dos grupos de alimentos. 
Tabela 3. Participação relativa (\%) dos grupos alimentares no VET diário das famílias das regiões metropolitanas de Curitiba e Porto Alegre, de acordo com o rendimento familiar per capita (em salários mínimos). $1995 / 1996$

\begin{tabular}{|c|c|c|c|c|c|c|c|c|c|c|c|c|c|c|c|c|c|c|c|c|}
\hline \multirow{3}{*}{ Grupos de alimentos } & \multicolumn{20}{|c|}{ Rendimento familiar per capita (em salários mínimos) } \\
\hline & \multicolumn{2}{|c|}{ Até 2} & \multicolumn{2}{|c|}{ De 2 a 3} & \multicolumn{2}{|c|}{ De 3 a 5} & \multicolumn{2}{|c|}{ De 5 a 6} & \multicolumn{2}{|c|}{ De 6 a 8} & \multicolumn{2}{|c|}{ De 8 a 10} & \multicolumn{2}{|c|}{ De 10 a 15} & \multicolumn{2}{|c|}{ De 15 a 20} & \multicolumn{2}{|c|}{ De 20 a 30} & \multicolumn{2}{|c|}{ Mais de 30} \\
\hline & Curi ${ }^{\star}$ & $\mathrm{POA}^{* *}$ & Curi & POA & Curi & POA & Curi & POA & Curi & POA & Curi & POA & Curi & POA & Curi & POA & Curi & POA & Curi & POA \\
\hline Cereais e derivados & 40,7 & 37,6 & 37,9 & 38,0 & 37,1 & 41,5 & 37,2 & 51,1 & 37,5 & 35,8 & 35,0 & 34,8 & 35,3 & 30,1 & 35,8 & 34,0 & 30,7 & 32,0 & 34,4 & 29,7 \\
\hline Raízes, tubérculos e derivados & 2,5 & 3,9 & 2,2 & 3,6 & 2,0 & 3,0 & 2,1 & 2,4 & 1,7 & 3,2 & 1,7 & 4,3 & 0,8 & 3,3 & 2,3 & 3,3 & 2,2 & 2,7 & 2,4 & 2,3 \\
\hline Carnes e embutidos & 11,0 & 13,2 & 10,7 & 11,1 & 12,0 & 11,2 & 11,5 & 10,2 & 12,1 & 13,5 & 15,2 & 14,2 & 14,8 & 12,7 & 12,0 & 13,7 & 16,5 & 17,7 & 14,0 & 15,5 \\
\hline Leguminosas & 4,8 & 2,5 & 2,1 & 1,6 & 2,0 & 1,6 & 2,3 & 1,1 & 1,7 & 1,4 & 1,5 & 1,5 & 2,2 & 1,2 & 2,1 & 1,5 & 0,8 & 1,0 & 1,6 & 0,7 \\
\hline Leite e derivados & 5,1 & 8,0 & 4,9 & 9,2 & 7,5 & 9,0 & 6,1 & 9,0 & 7,5 & 10,5 & 8,0 & 9,9 & 8,5 & 15,9 & 6,8 & 9,2 & 8,1 & 13,9 & 8,2 & 10,5 \\
\hline Ovos & 0,9 & 1,8 & 0,6 & 1,4 & 1,0 & 1,4 & 1,1 & 1,6 & 0,9 & 1,6 & 1,2 & 1,1 & 0,8 & 1,5 & 0,8 & 1,3 & 0,5 & 1,5 & 0,9 & 1,3 \\
\hline Verduras e legumes & 0,6 & 0,7 & 0,5 & 0,9 & 0,9 & 1,0 & 0,6 & 0,8 & 0,5 & 1,5 & 0,7 & 1,3 & 2,0 & 1,2 & 1,2 & 1,1 & 0,8 & 1,5 & 1,6 & 1,4 \\
\hline Frutas & 2,0 & 3,3 & 3,0 & 3,3 & 2,9 & 2,6 & 2,8 & 2,6 & 2,6 & 4,0 & 4,3 & 3,9 & 3,5 & 3,6 & 3,2 & 4,1 & 4,0 & 4,9 & 4,9 & 5,1 \\
\hline Açúcares e doces & 17,8 & 13,2 & 17,9 & 13,0 & 16,5 & 13,2 & 16,2 & 7,6 & 17,2 & 14,0 & 12,1 & 11,1 & 11,4 & 10,5 & 13,0 & 10,7 & 13,2 & 7,3 & 11,8 & 10,6 \\
\hline Óleos e gorduras vegetais & 11,6 & 12,0 & 17,5 & 14,6 & 14,2 & 12,1 & 16,3 & 10,5 & 13,8 & 9,7 & 15,3 & 12,7 & 14,8 & 14,0 & 18,0 & 14,4 & 15,0 & 6,0 & 12,1 & 10,1 \\
\hline Banha, touc., maion. e cr. de leite & 0,4 & 0,2 & 0,3 & 0,6 & 0,6 & 0,5 & 1,0 & 0,5 & 1,0 & 0,8 & 0,9 & 1,1 & 1,1 & 1,2 & 1,1 & 1,1 & 1,0 & 1,7 & 1,6 & 2,0 \\
\hline Oleaginosas & 0,2 & 0,4 & 0,5 & 0,2 & 0,1 & 0,2 & 0,1 & 0,1 & 0,2 & 0,2 & 0,1 & 0,0 & 0,3 & 0,3 & 0,5 & 0,3 & 0,9 & 0,4 & 0,5 & 0,4 \\
\hline Refrigerantes & 0,6 & 1,7 & 0,6 & 1,1 & 1,1 & 1,4 & 1,0 & 1,0 & 1,4 & 1,8 & 1,5 & 1,5 & 1,7 & 1,8 & 1,3 & 2,4 & 1,7 & 3,0 & 2,1 & 3,0 \\
\hline Bebidas Não alcoólicas & 0,3 & 0,5 & 0,6 & 0,5 & 0,5 & 0,4 & 0,5 & 0,4 & 0,5 & 0,6 & 0,5 & 0,7 & 0,4 & 0,5 & 0,3 & 0,5 & 0,4 & 0,7 & 0,5 & 0,5 \\
\hline Bebidas Alcoólicas & 1,2 & 0,9 & 0,1 & 0,5 & 0,7 & 0,6 & 0,5 & 0,5 & 0,6 & 0,9 & 0,8 & 1,3 & 0,6 & 1,4 & 0,5 & 0,8 & 2,4 & 1,7 & 1,1 & 1,4 \\
\hline Preparações prontas & 0,1 & 0,0 & 0,4 & 0,2 & 0,7 & 0,2 & 0,5 & 0,5 & 0,6 & 0,3 & 1,0 & 0,4 & 1,7 & 0,6 & 0,8 & 1,5 & 1,5 & 3,8 & 2,1 & 5,3 \\
\hline Condimentos & 0,2 & 0,1 & 0,2 & 0,2 & 0,2 & 0,1 & 0,2 & 0,1 & 0,2 & 0,2 & 0,2 & 0,2 & 0,1 & 0,2 & 0,3 & 0,1 & 0,3 & 0,2 & 0,2 & 0,2 \\
\hline Total & 100,0 & 100,0 & 100,0 & 100,0 & 100,0 & 100,0 & 100,0 & 100,0 & 100,0 & 100,0 & 100,0 & 100,0 & 100,0 & 100,0 & 100,0 & 100,0 & 100,0 & 100,0 & 100,0 & 100,0 \\
\hline
\end{tabular}

Fonte: Bleil (2004) baseado em IBGE (1998)

* Curi = Região Metropolitana de Curitiba (Paraná)

${ }^{*} \mathrm{POA}=$ Região Metropolitana de Porto Alegre (Rio Grande do Sul) 
Examinando os dados da Tabela 3 , verifica-se que a maior $(51,1 \%)$ participação dos cereais e derivados no VET, foi observada para as famílias com rendimentos entre 5 e 6 SM da RM de Porto Alegre. Em Curitiba, a maior participação (40,7\%) ocorre no grupamento mais pobre (até $2 \mathrm{SM}$ ). Verifica-se ainda uma redução, para as duas regiões analisadas, na participação no VET deste grupo alimentar, conforme ocorre o aumento da renda.

Ainda com base nos dados da Tabela 3, verifica-se que conforme aumenta a renda, ocorre uma maior participação no VET do grupo das carnes e embutidos e do leite e derivados. Comparando, concomitantemente, os dados de ambas regiões, Porto Alegre apresenta maior disponibilidade dos referidos grupos. Conforme discutido anteriormente, as fontes protéicas de origem animal, tais como as carnes, apresentam-se em maior proporção em ambas regiões, para as famílias com os maiores estratos de renda.

Monteiro, Mondini e Costa (2000) verificaram uma maior participação das carnes no VET diário das onze famílias das RM integrantes da POF, quando comparados os resultados da POF 1987/88 com os dados obtidos em 1995/96 (evolução de $10,5 \%$ para $13 \%$, durante o período).

Galleazzi, Domene e Sichieri (1997), tendo por base dados do estudo multicêntrico realizado em cinco capitais brasileiras, observaram um aumento no consumo de queijo, frango e carne, quando comparado ao estudo realizado pelo ENDEF, em 1974 e a POF de 1987.

Faganello (2002) confirma em sua pesquisa, que a renda é um fator importante na disponibilidade alimentar e na participação dos grupos de alimentos no VET diário.

Com relação às leguminosas, verifica-se participação das mesmas no VET em torno de $2,1 \%$ na RM de Curitiba e 1,4\% na RM de Porto Alegre. É maior a participação das leguminosas no VET das famílias com menor renda, o que sugere que o hábito de consumir arroz com feijão revela menor presença entre as famílias com maiores rendimentos. 
Faganello (2002) verificou que no estrato de menor renda (até 2 SM) a participação das leguminosas no VET diário foi de 1,8\% e 2,5\% para famílias da RM de São Paulo e de Recife, respectivamente. No grupamento acima de 30 SM, o referido autor também observou uma reduzida participação das leguminosas (0,7\% em São Paulo e 2,1\% em Recife).

Cabe citar que, de acordo com Hoffmann (1995), o consumo do feijão teve uma redução significativa, ao longo de duas décadas, principalmente em regiões urbanizadas.

A queda no consumo de feijão pode estar associada com a crescente participação da mulher no mercado de trabalho, uma vez que o tempo gasto para o preparo deste alimento é grande e com isso as mulheres, ainda majoritariamente responsáveis pelo preparo de alimentos nos domicílios brasileiros, acabam optando por alternativas mais simples para sua preparação e consumo (Silva, 1996).

Ao analisar os dados referentes à participação de verduras e legumes no VET disponível para as famílias, ressalta-se a menor importância que é reservada a este grupo; nas RM de Curitiba e Porto Alegre, aproximadamente $1 \%$ da contribuição no VET é fornecida pelo referido grupo. Parece não haver diferença expressiva entre os estratos de renda nas duas regiões estudadas, o que sugere que a renda não exerce influência decisiva no consumo deste grupo de alimentos, e sim outras variáveis, como por exemplo, a cultura e nível de informação da população.

De acordo com Philippi et al. (1999), o consumo recomendado de hortaliças para um indivíduo adulto é de 4 a 5 porções diárias. Considerando que em média uma porção de hortaliças fornece em torno de $15 \mathrm{kcal}$, a participação correspondente a este grupo de alimentos deveria suprir aproximadamente $3 \%$ do VET (cerca de $75 \mathrm{kcal}$ ) a fim de se aproximar ao máximo do atendimento das necessidades de vitaminas e minerais essenciais ao organismo. 
Trudeau et al. (1998) citam que deveriam ser implementadas intervenções que focalizassem especialmente o consumo de hortaliças, pois trazem indiscutíveis benefícios fisiológicos para grupos populacionais de todas as idades.

Craig (1997), após extensa revisão de pesquisas sobre a importância dos fitoquímicos como protetores da saúde, identificou nos resultados de $82 \%$ das mesmas, que o consumo de frutas e hortaliças tem efeito significativo na proteção contra diversos tipos de câncer.

Cabe destacar que a participação das frutas apresenta-se em situação de relativa vantagem, se comparada às verduras e legumes. Na RM de Curitiba, em média 3,3\% do VET é proveniente das frutas e na RM de Porto Alegre a participação situa-se em torno de $3,7 \%$. Não foi verificada diferença expressiva entre os dados obtidos para as duas regiões, porém observa-se uma tendência crescente de sua participação, conforme aumenta o rendimento familiar. Faganello (2002) em seu estudo nas RM de São Paulo e Recife, também encontrou tendência similar. Este autor observou ainda um maior consumo na RM de São Paulo (4,3\% - média dos 3 estratos de renda analisados), quando comparado com os resultados de Recife $(3,7 \%)$.

Neves, Chaddad e Lazzarini (2000) referem que "cada vez mais aumenta o consumo de frutas, produtos saudáveis, alimentos frescos, com menores teores de colesterol, gordura, sal e outras substâncias que possam retardar os danos à saúde".

No entanto cabe lembrar que o aumento no consumo desses alimentos ocorre de forma mais expressiva entre os indivíduos com maiores rendimentos e que também detêm maior acervo de informações sobre saúde, nutrição e qualidade de vida.

Francischini et al. (2000) apontam para a importância, entre outros fatores, de subsídios para produtores de alimentos com pouca densidade energética, especialmente frutas e vegetais, como estratégia para o estímulo ao consumo e conseqüente intervenção preventiva sobre a obesidade. 
Sugere-se que a demanda por proteína e gordura tem associação com doenças infecciosas e pode ser uma ameaça para a população mais pobre e também para o ecossistema. Por outro lado, o aumento da produção de frutas e hortaliças e a prática do consumo domiciliar, poderiam incorrer em ganhos à saúde e ao desenvolvimento sustentável (Schirnding \& Yach, 2002).

Um resultado que merece destaque é a participação do grupo dos açúcares e doces no VET diário das famílias. Na RM de Curitiba a maior participação $(17,9 \%)$ foi verificada no estrato de 2 a 3 SM e em Porto Alegre no grupamento entre 6 e 8 SM ocorreu a maior participação (14\%).

Mondini \& Monteiro (1994) analisaram a participação do açúcar na dieta dos brasileiros, nas regiões nordeste e sudeste, tendo por base três inquéritos nacionais (POF - 1961/63, ENDEF - 1974/75 e POF - 1987/88) e observaram que o mesmo tem participação de $25 \%$ no total dos carboidratos. Os autores chamam a atenção para o consumo insuficiente de carboidratos complexos, pela população brasileira.

Marchioni \& Zacarelli (2002) enfatizam a importância do acesso pela população à diversidade dietética, a qual tem provocado um aumento no consumo de óleos vegetais e açúcares. Destacam também que o grande desafio para os profissionais da saúde, ciência de alimentos e economia é subsidiar o planejamento de programas de crescimento econômico e de prevenção ou retardo dos efeitos indesejáveis para a saúde, os quais não são aqueles exclusivamente relacionados à pobreza e desnutrição e sim aqueles relacionados aos excessos alimentares.

Cabe registrar que Rosado e Monteiro (2001) salientam que o uso do açúcar simples está relacionado ao aumento do índice glicêmico, o que representa um fator de risco para o desenvolvimento de doenças cardiovasculares, diabetes e obesidade.

Também Sartorelli \& Franco (2003) enfatizam que a prevalência de Diabetes Mellitus (DM) tipo 2 tem se elevado vertiginosamente em todo o mundo. Na América Latina há um incremento nas faixas etárias mais jovens e 
no Brasil, as modificações no consumo alimentar que têm ocorrido, com alimentação pobre em fibras e rica em açúcares, aliadas ao sedentarismo, têm sido referidas como os principais fatores etiológicos da obesidade, DM tipo 2 e também outras doenças crônicas.

Por outro lado, cabe registrar que Benton (1996) destaca que o aumento da glicose sanguínea exerce influencia positiva na memória e que o hábito de tomar café da manhã contribui para um melhor rendimento intelectual de estudantes.

Segundo Bleil (1998) a carne é considerada o elemento central na alimentação, por ter características de ser substanciosa, levar a saciedade e exibir ascensão social. Por outro lado, o açúcar transformou-se em símbolo de riqueza e ainda hoje é um alimento marcante na mesa do brasileiro.

Com relação ao grupo integrado pela banha, toucinho, maionese e creme de leite (fontes expressivas de gordura animal), a participação média foi de 0,9\% e 1,0\% no VET da RM de Curitiba e Porto Alegre, respectivamente. Observa-se que praticamente não existe diferença entre as duas regiões. Por outro lado, quando se analisam os dados relativos aos estratos de renda separadamente, verifica-se uma maior participação deste grupo de alimentos nos estratos de maior de renda, chegando a alcançar $1,6 \%$ no estrato de mais de $30 \mathrm{SM}$ em Curitiba e 2,0\% no mesmo estrato de renda, para as famílias da RM de Porto Alegre.

Mondini \& Monteiro (1994) já haviam verificado o decréscimo no consumo de banha e toucinho de $4,9 \%$ para $1,0 \%$, quando compararam os dados de três inquéritos nacionais realizados entre os anos de 1962 e 1988.

Quanto ao grupo das oleaginosas, a sua participação é pequena no VET diário (média de 0,3\% em Curitiba e Porto Alegre). Este resultado reflete a inexistência do hábito da população em consumir este tipo de produto, fato que possivelmente, tem entre seus condicionantes o elevado custo do mesmo, o que dificulta a sua aquisição para a maioria da população. 
Com relação às bebidas, os refrigerantes apresentaram uma participação média de $1,3 \%$ no VET da RM de Curitiba, sendo que a menor participação ocorreu nos estratos mais pobres (até $2 \mathrm{SM}$ e de 2 a $3 \mathrm{SM}$ ) e a maior participação foi observada entre as famílias integrantes do estrato mais rico (acima de $30 \mathrm{SM}$ ). Entre as famílias da RM de Porto Alegre, a participação média foi superior a de Curitiba (1,9\%) com limite mínimo de 1,0\% no estrato de renda de 5 a 6 SM e máximo de $3,0 \%$ nos estratos de 20 a 30 SM e mais de 30 SM. Mais uma vez é observado uma tendência crescente da participação do grupo dos refrigerantes, em grupos populacionais com maiores rendimentos. Outro dado interessante é a maior participação deste grupo quando comparado ao grupo das verduras e legumes.

Tomita \& Cardoso (2002) ao analisarem a participação dos refrigerantes no VET diário de uma população adulta no município de São Paulo, verificaram uma participação de 2,5\%.

Fisberg, Amâncio e Lottenberg (2002) referem que o uso do refrigerante por crianças e adolescentes é um tema controverso, principalmente pelo fato de ser um produto de grande aceitação entre os consumidores e sugerem que o consumo destes, seja mantido em doses moderadas para que desse modo, seja amenizado o comprometimento da saúde.

Nesta pesquisa, analisou-se a participação no VET do grupo das bebidas não alcoólicas. Nesse grupo foram incluídos os sucos artificiais, refrescos, chá e café. Verificou-se menor participação, quando comparada aos refrigerantes. Nas duas RM, a participação no VET foi de $0,5 \%$ e não foi verificada diferença expressiva quando se analisou a participação de acordo com os estratos de renda das famílias.

Ainda tendo por base os dados da Tabela 3, observa-se que para as bebidas alcoólicas (incluído neste grupo aguardente, vinho, cerveja e uísque), a participação foi superior quando comparado ao grupo das bebidas não alcoólicas. A menor participação $(0,1 \%)$ foi verificada para famílias do estrato de renda entre 2 e 3 SM em Curitiba. Verificou-se ainda uma tendência de maior 
consumo nos estratos de renda mais elevados, principalmente para as famílias da RM de Porto Alegre. Também o tipo de bebida adquirida sofre influência da renda; nas camadas mais elevadas o vinho e o uísque aparecem em maior proporção e nas menores, há maior participação da aguardente no VET.

Almeida \& Coutinho (1993) ao estudarem o consumo de bebidas alcoólicas, tendo como amostra uma população com idade acima de 13 anos, moradora da região metropolitana do Rio de Janeiro, identificaram uma freqüência esporádica de $51 \%$ para o consumo de bebidas alcoólicas naquela população. Também encontraram maiores índices de abstinência em indivíduos com níveis de renda inferiores.

Mondini \& Monteiro (1994) enfatizaram a necessidade de estudar o consumo de bebidas alcoólicas, com a hipótese de que o gasto com este tipo de produto tem revelado tendência de crescimento.

As preparações prontas aparecem com maior participação nos dois últimos estratos de renda, principalmente na RM de Porto Alegre. A média da participação deste grupo foi de $0,9 \%$ em Curitiba e 1,3\% em Porto Alegre. No estrato de renda de mais de $30 \mathrm{SM}$, a participação foi de 2,1\% para Curitiba e $5,3 \%$ para Porto Alegre, valores estes bem superiores à média observada. Cabe ressaltar que no estrato de menor renda (até 2 SM), a participação deste grupo no VET foi de $0,1 \%$ em Curitiba. Em Porto Alegre não foi observada a participação do grupo no VET diário, quando se considerou o mesmo estrato de renda.

Com relação ao grupo dos condimentos, sua participação no VET foi, conforme esperado, a menor entre todos os grupos (média de $0,2 \%$ para as duas RM).

Silva (1991) relata que a intensa urbanização, a inserção da mulher no mercado de trabalho, o desenvolvimento da agroindústria e os planos de ajustes econômicos proporcionaram, especialmente na década de 90, mudanças no consumo alimentar da população brasileira, principalmente aquelas relacionadas ao consumo de alimentos fora do domicílio e de produtos 
prontos ou semiprontos. Este mesmo autor refere que na região sul (especificamente Porto Alegre), ocorreu um aumento de gastos com alimentação fora do domicílio, sendo que a população de menor renda optava por este tipo de refeição, comercializada, principalmente, em restaurantes populares cujos preços eram mais acessíveis. Com isto, ocorreu um incremento no comércio de alimentos e também crescimento do número de vendedores ambulantes, o que torna necessário uma atuação mais efetiva da Vigilância Sanitária com o intuito de assegurar à população acesso aos alimentos mais seguros.

Martins (1998) destaca que entre o período de 1974/75 e 1987/88 a participação das despesas com alimentação fora do domicílio teve um incremento de $25 \%$, considerando o total de despesas com a alimentação. Com isto, houve redução no consumo médio per capita de arroz, feijão, batata, tomate, alface, leite não pasteurizado, leite em pó, açúcar, pão francês e macarrão. Inversamente, os produtos que aumentaram o consumo foram leite pasteurizado, carne de frango, frutas, queijos, cebola e ovos.

Bermudez \& Tucker (2003) também destacam as mudanças alimentares ocorridas, envolvendo a população da América Latina e em especial a brasileira, com tendência ao incremento no consumo de gorduras totais, produtos de origem animal e de açúcar e menor ingestão de cereais, frutas e vegetais.

Com a melhoria da renda e a crescente urbanização, ocorre um aumento no acesso e consumo de alimentos refinados, ricos em gorduras saturadas e açúcar (Marchioni \& Zacarelli, 2002)

Oliveira (1997) refere que no Brasil, as mudanças nos padrões alimentares foram condicionadas, em parte por "imitação" dos padrões internacionais de consumo e que não representam mudanças que incluem práticas predominantemente saudáveis de alimentação. Esta afirmação é respaldada por Garcia (2003), que ressalta que o padrão alimentar 
característico de países desenvolvidos é atualmente uma preocupação dos países em desenvolvimento.

Registra-se ainda as considerações de Lustosa \& Figueiredo (1990) que destacaram que a inadequação alimentar pode ocorrer em larga escala, independente do nível de despesa familiar.

\subsection{Análise da participação dos alimentos in natura e industrializados}

Nesta seção serão analisados os resultados relativos à classificação (in natura ou industrializados) dos alimentos. Cabe lembrar que neste trabalho, considerou-se produto industrializado todo alimento que passou por algum tipo de processamento, que alterou suas características iniciais. Os alimentos considerados in natura foram: frutas, hortaliças, leguminosas, arroz, oleaginosas, carnes não processadas, ovos e o leite fresco.

A Tabela 4 mostra a participação de alimentos in natura $\mathrm{e}$ industrializados no VET disponível para as famílias das RM de Curitiba e Porto Alegre. 
Tabela 4. Participação relativa de alimentos in natura e industrializados (\%) nos domicílios de Curitiba e Porto Alegre, de acordo com o estrato de recebimento familiar. 1995/1996

\begin{tabular}{|c|c|c|c|c|c|c|c|c|c|c|}
\hline \multirow{2}{*}{$\begin{array}{c}\text { Região } \\
\text { Metropolitana } \\
\text { Origem do } \\
\text { alimento }\end{array}$} & \multicolumn{10}{|c|}{ Estratos de Recebimento (em salários mínimos) } \\
\hline & $\begin{array}{c}\text { Até } \\
2\end{array}$ & $\begin{array}{c}\text { Mais } \\
\text { de } \\
2 \text { a } 3\end{array}$ & $\begin{array}{c}\text { Mais } \\
\text { de } \\
3 \text { a } 5\end{array}$ & $\begin{array}{c}\text { Mais } \\
\text { de } \\
5 \text { a } 6\end{array}$ & $\begin{array}{c}\text { Mais } \\
\text { de } \\
6 \text { a } 8\end{array}$ & $\begin{array}{c}\text { Mais } \\
\text { de } \\
8 \text { a } 10\end{array}$ & $\begin{array}{c}\text { Mais } \\
\text { de } \\
10 \text { a } 15\end{array}$ & $\begin{array}{c}\text { Mais } \\
\text { de } \\
15 \text { a } 20\end{array}$ & $\begin{array}{c}\text { Mais } \\
\text { de } \\
20 \text { a } 30\end{array}$ & $\begin{array}{c}\text { Mais } \\
\text { de } \\
30\end{array}$ \\
\hline \multicolumn{11}{|l|}{ Curitiba: } \\
\hline In natura & 18,7 & 17,6 & 17,4 & 17,5 & 17,4 & 21,6 & 21,1 & 19,0 & 22,7 & 23,8 \\
\hline Industrializado & 81,3 & 82,4 & 82,6 & 82,5 & 82,6 & 78,4 & 78,9 & 81,0 & 77,3 & 76,2 \\
\hline \multicolumn{11}{|l|}{ Porto Alegre: } \\
\hline In natura & 22,2 & 19,2 & 19,7 & 14,1 & 23,5 & 23,8 & 20,3 & 22,2 & 25,5 & 22,4 \\
\hline Industrializado & 77,8 & 80,8 & 80,3 & 85,9 & 76,5 & 76,2 & 79,7 & 77,8 & 74,5 & 77,6 \\
\hline
\end{tabular}

Fonte: Bleil (2004) baseado em IBGE (1998)

Os dados revelam que a participação de alimentos in natura se mostrou ligeiramente superior para as famílias pertencentes aos estratos de maior renda. Registra-se que, quando se considera o conjunto dos dez estratos de renda, cerca de $20,5 \%$ do alimento disponível para consumo nesta população, integrante da amostra, provém de fontes in natura. Para as famílias da RM de Curitiba, a participação no VET, dos referidos alimentos é, em média, $20 \%$. No estrato de renda entre 3 e 5 SM verifica-se a menor oferta (17\%) e para o grupo de renda mais elevada (acima de $30 \mathrm{SM}$ ), a participação dos alimentos in natura alcança $24 \%$.

Vale salientar ainda que nesta pesquisa não foi analisado o consumo de alimentos fora do domicílio, o que possivelmente contribuiria para a elevação da participação dos alimentos industrializados.

Registra-se que, no tocante à alimentação fora do domicílio, especialmente entre os grupos de renda baixa e intermediária, freqüentemente a opção recai para a refeição identificada como "almoço". O café da manhã, assim como o jantar são opções menos freqüentes entre o referido grupamento (Branco, 2000). 
Destaca-se também que as análises relativas ao consumo de alimentos fora do domicílio mostraram reduzida variabilidade e elevado consumo de lipídeos, ácidos graxos saturados, proteína de origem animal e baixa ingestão de ácidos graxos poliinsaturados (Branco, 2000).

Oliveira \& Thébaud-Mony (1998) em pesquisa implementada no município de São Paulo, identificaram incremento no consumo de produtos industrializados, embora os entrevistados tivessem relatado preferência por produtos frescos em relação aos industrializados.

Bertasso (2000) tendo por base os dados da POF 1995/1996, avaliou o comportamento de amostra de famílias com relação ao consumo de alimentos tradicionais (consumo e preparo no próprio domicílio) e os alimentos classificados pelo autor como "modernos" (consumo fora do domicílio). De acordo com o autor há uma tendência dos grupamentos integrados por mulheres que estão inseridas no mercado de trabalho, os grupos com idade de 21 a 30 anos e famílias compostas de maneira não tradicional (por exemplo sem filhos, sem parentes ou sem empregados), de revelar maior consumo de "alimentos modernos". Os grupos formados por indivíduos mais idosos (51 anos ou mais) mostraram preferência por refeições tradicionais. Ainda segundo o referido autor, a renda tem papel decisivo no consumo alimentar entre os brasileiros. Isto se justifica pelo fato do custo de mão de obra e de tecnologia serem incorporados nos preços das refeições prontas ou semi-prontas.

Belik, Silva e Takagi (2001) verificaram um aumento dos gastos com produtos industrializados, decorrentes principalmente da urbanização e das mudanças ocorridas nos hábitos alimentares da população, associado às alterações na estrutura familiar e no mercado de trabalho. Também Maluf (2000) relata que o gasto com alimentação fora de casa chegou a quase $12 \%$ do orçamento em 1999, principalmente nas classes de renda mais baixas.

Bleil (1998) registra que no Brasil, existe uma tendência de consumo semelhante a dos países desenvolvidos. As conseqüências são o aumento no consumo de produtos industrializados, principalmente de congelados, enlatados 
e refrigerantes. O autor enfatiza também que o "hábito de consumir produtos cada vez mais industrializados é uma marca da modernidade".

É importante salientar que mudanças no consumo alimentar da população brasileira tem revelado ritmo veloz, com redução no consumo de alimentos considerados "naturais" como é o caso do feijão com arroz, vegetais e frutas. Por outro lado, observa-se aumento do consumo de refeições semiprontas, ricas em energia, gorduras e com baixo conteúdo de fibras (Monteiro; Mondini e Costa, 2000).

\subsection{Análise da disponibilidade de fibras e colesterol}

Na Tabela 5 são mostrados dados relativos à disponibilidade de fibras e colesterol nas famílias das RM de Curitiba e Porto Alegre.

Tabela 5. Disponibilidade diária de fibra $(\mathrm{g})$ e colesterol $(\mathrm{mg})$ nos domicílios das regiões metropolitanas de Curitiba e Porto Alegre, de acordo com o recebimento familiar per capita (em salários mínimos) 1995/1996

\begin{tabular}{|c|c|c|c|c|c|c|c|c|c|c|}
\hline \multirow[b]{2}{*}{ Nutriente } & \multirow[b]{2}{*}{$\begin{array}{c}\text { Até } \\
2\end{array}$} & \multicolumn{9}{|c|}{ Estrato de Recebimento (em salários mínimos) } \\
\hline & & $\begin{array}{c}\text { Mais } \\
\text { de } \\
2 \text { a } 3 \\
\end{array}$ & $\begin{array}{c}\text { Mais } \\
\text { de } \\
3 \text { a } 5 \\
\end{array}$ & $\begin{array}{c}\text { Mais } \\
\text { de } \\
5 \text { a } 6\end{array}$ & $\begin{array}{c}\text { Mais } \\
\text { de } \\
6 \text { a } 8 \\
\end{array}$ & $\begin{array}{c}\text { Mais } \\
\text { de } \\
8 \text { a } 10\end{array}$ & $\begin{array}{c}\text { Mais } \\
\text { de } \\
10 \text { a } 15 \\
\end{array}$ & $\begin{array}{c}\text { Mais } \\
\text { de } \\
15 \text { a } 20 \\
\end{array}$ & $\begin{array}{c}\text { Mais } \\
\text { de } \\
20 \text { a } 30 \\
\end{array}$ & $\begin{array}{c}\text { Mais } \\
\text { de } \\
30 \\
\end{array}$ \\
\hline \multicolumn{11}{|l|}{ Curitiba } \\
\hline \multirow{2}{*}{$\begin{array}{l}\text { Fibra }(\mathrm{g}) \\
\text { Colesterol } \\
\text { (mg) } \\
\text { Porto } \\
\text { Alegre }\end{array}$} & 7,1 & 6,4 & 6,6 & 6,8 & 6,5 & 7,1 & 7,4 & 8,6 & 8,0 & 10,6 \\
\hline & 166,9 & 113,1 & 134,0 & 170,7 & 146,2 & 171,6 & 174,0 & 155,8 & 161,3 & 212,7 \\
\hline \multirow{2}{*}{$\begin{array}{l}\text { Fibra }(\mathrm{g}) \\
\text { Colesterol } \\
(\mathrm{mg})\end{array}$} & 5,8 & 6,8 & 7,0 & 5,8 & 6,7 & 6,4 & 7,7 & 9,3 & 7,6 & 8,6 \\
\hline & 155,8 & 186,6 & 171,9 & 166,7 & 180,0 & 245,0 & 162,1 & 199,7 & 212,3 & 167,7 \\
\hline
\end{tabular}

Fonte: Bleil (2004) baseado em IBGE (1998)

A análise da disponibilidade de fibras nos domicílios das famílias revela dados preocupantes. Nas duas regiões, para nenhum dos estratos de renda a 
disponibilidade de fibras se aproxima do recomendado (25 g/dia). Na RM de Curitiba, a maior disponibilidade de fibra apresenta-se no estrato de renda acima de $30 \mathrm{SM}$ (10,6 g/dia) e a menor disponibilidade encontra-se no estrato de renda de mais de 2 a 3 SM (6,4 g/dia). Na RM de Porto Alegre, entre os mais pobres (renda de até $2 \mathrm{SM}$ ) encontra-se a menor disponibilidade $(5,8 \mathrm{~g} / \mathrm{dia})$ de fibra, enquanto a maior aparece no estrato de renda de mais de 15 a 20 SM (9,3 g). Observa-se que na RM de Curitiba parece haver uma maior disponibilidade de fonte dietética de fibra quando comparada a RM de Porto Alegre. Porém em ambas regiões, a disponibilidade é inferior ao preconizado pela literatura, não atingindo $50 \%$ da recomendação (National Academy of Sciences, 2003). Também parece existir uma correlação entre a disponibilidade de fibras e o aumento na renda, pois a maior disponibilidade desta ocorre nos domicílios onde residem as famílias com rendimentos mais elevados.

Estudo envolvendo amostra de adultos do município de Cotia (SP), realizado por Mattos \& Martins (2000), revelou resultados mais favoráveis, quando comparados às análises do presente estudo. Naquele município foi verificado um consumo médio de $24 \mathrm{~g}$ de fibras totais /dia, com predomínio de fibras insolúveis $(17 \mathrm{~g})$. Estas fibras foram provenientes principalmente do consumo de feijões. É importante ressaltar que existe uma associação entre o baixo consumo de feijão e conseqüentemente de fibras insolúveis. Tal situação pode contribuir para problemas intestinais que surgiram nos últimos anos, com maior freqüência, entre a população adulta. Os referidos autores concluem que apesar da escassez de pesquisas sobre o assunto, é possível inferir que o consumo de fibras alimentares por expressiva parcela da população de São Paulo apresenta-se inferior ao recomendado, provavelmente, em decorrência das mudanças no padrão de alimentação.

Faganello (2002) ao analisar o conteúdo de fibras disponível nos domicílios das famílias de São Paulo e Recife, verificou também uma baixa disponibilidade de fibras para os grupamentos (máximo de $10,0 \mathrm{~g}$ e $13,8 \mathrm{~g}$ respectivamente, no maior estrato de renda analisado). 
Segundo Lajolo et al. (2001) a importância das fibras foi reconhecida a mais de duas décadas na prevenção de diversas doenças, como por exemplo, prisão de ventre, hemorróidas, câncer de cólon, arteriosclerose e diabetes, ressaltando a necessidade de se adotar hábitos alimentares que estimulem o consumo de fibras pela população.

Por outro lado, as fibras contêm um componente denominado ácido fítico, o qual está correlacionado com carências de cálcio e zinco, principalmente em crianças que consomem pouco leite e grande quantidade de produtos elaborados com farinhas integrais (Kritchevsky, Bonfiel e Anderson, 1988).

Ainda tendo por base a Tabela 5, foi analisada a disponibilidade de colesterol nos domicílios das famílias das RM de Curitiba e Porto Alegre. Observa-se que as famílias da RM de Porto Alegre apresentam média diária superior à RM de Curitiba (184,8 mg e 160,6 mg, respectivamente) com valores máximos de $245 \mathrm{mg}$ entre as famílias do estrato de renda de mais de 8 a $10 \mathrm{SM}$ (Porto Alegre) e de 212,7 mg, entre os mais ricos (renda acima de $30 \mathrm{SM}$ ) em Curitiba. Cabe ressaltar que nenhum dos estratos de renda nas duas RM alcançou o limite de colesterol dietético preconizado que é de $300 \mathrm{mg} / \mathrm{dia}$ (NAS, 2003).

Cabral et al. (2003) encontraram uma média de consumo de colesterol diário de 202mg em uma população de hipertensos com idade entre 18 e 74 anos, atendidos em ambulatório do Hospital das Clínicas da Universidade Federal de Pernambuco. Os dados revelam que os limites de ingestão de colesterol não foram atingidos, o que possivelmente sugere preocupação da referida população com a redução no consumo de produtos de origem animal e com doenças cardiovasculares.

Cervatto, Mazzilli e Martins (1997) analisaram a dieta habitual de uma população adulta em um município de São Paulo (SP) e verificaram que os limites preconizados de colesterol eram atendidos por apenas $5 \%$ das dietas, indicando consumo indevidamente superior ao recomendado. 
Dados obtidos junto a estudantes universitários do Uruguai (país vizinho do estado do Rio Grande do Sul) revelaram que a prevalência de hipercolesterolemia foi de $14,4 \%$ nesta população e que $27,5 \%$ das famílias tinham prevalência de antecedentes familiares para a doença (Girotto et al., 1996).

Coronelli \& Moura (2003), em um estudo para identificar os fatores de risco para hipercolesterolemia em escolares de 7 a 10 anos, no município de Campinas (SP), verificaram que as crianças apresentaram (em média) colesterol sérico de $215 \mathrm{mg} / \mathrm{dl}$, sendo que valores iguais ou superiores a 200 $\mathrm{mg} / \mathrm{dl}$ são considerados elevados. Este estudo concluiu ainda que a obesidade apresenta-se como um fator de risco importante para o desenvolvimento da hipercolesterolemia.

Segundo Cardoso, Martins e Fornari (2002) a hipercolesterolemia ( $\geq 200 \mathrm{mg} / \mathrm{dl}$ de colesterol sanguíneo) é considerada um fator de risco para o desenvolvimento de doença isquêmica do coração. Porém, esta pode ser controlável, quando é feito o monitoramento da ingestão de colesterol diário.

Lessa, Conceição e Souza (1997) sugerem em seu estudo que as dislipidemias (incluindo a hipercolesterolemia) são importantes fatores de risco para o desenvolvimento de aterosclerose.

\subsection{Análise da disponibilidade de vitaminas e minerais}

Os resultados relativos à disponibilidade de vitaminas nos domicílios das famílias podem ser visualizados nas Tabelas 6 e 7 . 
Tabela 6. Disponibilidade de vitaminas nos domicílios das regiões metropolitanas de Curitiba e Porto Alegre (POA), de acordo com o estrato de recebimento familiar per capita (em salários mínimos), de até 2 SM até mais de 6 a 8 SM. 1995/1996.

\begin{tabular}{|c|c|c|c|c|c|c|c|c|c|c|}
\hline \multirow{3}{*}{ Vitamina } & \multicolumn{10}{|c|}{ Estrato de Recebimento (em salários mínimos) } \\
\hline & \multicolumn{2}{|c|}{ Até 2} & \multicolumn{2}{|c|}{ Mais de 2 a 3} & \multicolumn{2}{|c|}{ Mais de 3 a 5} & \multicolumn{2}{|c|}{ Mais de 5 a 6} & \multicolumn{2}{|c|}{ Mais de 6 a 8} \\
\hline & Curitiba & POA & Curitiba & POA & Curitiba & POA & Curitiba & POA & Curitiba & POA \\
\hline Vitamina $A(\mu \mathrm{g})$ & 800,9 & 1983,6 & $1.006,9$ & $3.528,5$ & $2.004,8$ & $3.637,0$ & $2.541,4$ & $2.211,9$ & 2018,7 & 3989,8 \\
\hline Vitamina C (mg) & 34,7 & 31,9 & 50,8 & 43,5 & 44,0 & 44,1 & 51,9 & 47,4 & 43,0 & 53,0 \\
\hline Vitamina B1 (mg) & 316,2 & 157,8 & 236,1 & 217,0 & 194,6 & 215,6 & 268,6 & 138,3 & 225,9 & 196,5 \\
\hline Vitamina B2 (mg) & 235,1 & 157,4 & 183,0 & 202,9 & 161,0 & 215,8 & 208,3 & 155,2 & 174,4 & 201,0 \\
\hline Vitamina B6 (mg) & 0,3 & 3,2 & 1,9 & 4,0 & 1,5 & 10,9 & 3,5 & 11,7 & 1,9 & 9,5 \\
\hline Vitamina B12 (mg) & 1,0 & 2,0 & 1,1 & 1,0 & 1,3 & 2,1 & 1,9 & 1,2 & 1,6 & 1,3 \\
\hline Vitamina D $(\mu \mathrm{g})$ & 0,0 & 0,0 & 0,0 & 1,1 & 0,0 & 0,5 & 1,0 & 0,7 & 0,9 & 2,3 \\
\hline Niacina (mg) & 13,4 & 10,0 & 10,5 & 12,7 & 11,3 & 12,3 & 12,4 & 9,2 & 12,1 & 12,3 \\
\hline Folacina $(\mu g)$ & 49,3 & 42,0 & 48,4 & 52,0 & 51,6 & 51,2 & 62,3 & 53,5 & 55,4 & 61,4 \\
\hline Ácido pant. (mg) & 1,0 & 23,8 & 13,7 & 28,7 & 10,1 & 82,0 & 25,6 & 88,0 & 13,7 & 70,5 \\
\hline Vitamina E (mg) & 14,3 & 14,5 & 22,3 & 22,3 & 16,6 & 32,8 & 26,0 & 33,1 & 19,3 & 27,1 \\
\hline
\end{tabular}

Fonte: Bleil (2004) baseado em IBGE (1998) 
Tabela 7. Disponibilidade de vitaminas nos domicílios das regiões metropolitanas de Curitiba e Porto Alegre (POA), de acordo com o estrato de recebimento familiar per capitã (em salários mínimos) de mais de 8 a 10 SM até mais de 30 SM 1995/1996

\begin{tabular}{|c|c|c|c|c|c|c|c|c|c|c|}
\hline \multirow{3}{*}{ Vitamina } & \multicolumn{10}{|c|}{ Estrato de Recebimento (em salários mínimos) } \\
\hline & \multicolumn{2}{|c|}{ Mais de 8 a 10} & \multicolumn{2}{|c|}{ Mais de 10 a 15} & \multicolumn{2}{|c|}{ Mais de 15 a 20} & \multicolumn{2}{|c|}{ Mais de 20 a 30} & \multicolumn{2}{|c|}{ Mais de 30} \\
\hline & Curitiba & POA & Curitiba & POA & Curitiba & POA & Curitiba & POA & Curitiba & POA \\
\hline Vitamina A $(\mu g)$ & $3.574,9$ & $3.273,9$ & $2.636,5$ & $4.211,9$ & $4.643,6$ & $4.238,1$ & $3.989,9$ & $4.500,2$ & 5461,0 & 5101,9 \\
\hline Vitamina C (mg) & 58,3 & 51,3 & 65,9 & 63,4 & 68,7 & 69,6 & 79,8 & 67,4 & 103,5 & 83,8 \\
\hline Vitamina B1 (mg) & 220,8 & 197,4 & 267,6 & 192,4 & 256,2 & 211,7 & 226,1 & 154,6 & 303,8 & 242,2 \\
\hline Vitamina B2 (mg) & 181,8 & 200,7 & 197,2 & 161,4 & 188,3 & 191,8 & 179,4 & 109,2 & 232,7 & 185,5 \\
\hline Vitamina B6 (mg) & 2,1 & 8,9 & 1,0 & 2,5 & 2,8 & 2,4 & 1,7 & 2,0 & 0,6 & 1,5 \\
\hline Vitamina B12 (mg) & 3,7 & 2,2 & 2,4 & 2,1 & 2,9 & 2,1 & 2,9 & 3,8 & 2,9 & 2,5 \\
\hline Vitamina D $(\mu \mathrm{g})$ & 1,0 & 1,8 & 1,7 & 0,0 & 1,7 & 2,1 & 2,3 & 0,0 & 0,4 & 3,8 \\
\hline Niacina (mg) & 12,5 & 12,8 & 14,6 & 12,9 & 14,4 & 15,4 & 16,1 & 11,1 & 18,9 & 15,0 \\
\hline Folacina $(\mu \mathrm{g})$ & 62,9 & 52,2 & 68,6 & 68,6 & 75,5 & 72,6 & 84,4 & 74,4 & 97,6 & 81,4 \\
\hline Ácido pant. (mg) & 14,5 & 66,4 & 6,2 & 17,2 & 19,0 & 16,0 & 10,2 & 12,7 & 1,8 & 8,3 \\
\hline Vitamina E (mg) & 20,0 & 28,1 & 19,7 & 20,6 & 28,9 & 21,9 & 21,9 & 9,9 & 19,0 & 16,0 \\
\hline
\end{tabular}

Fonte: Bleil (2004) baseado em IBGE (1998) 
Tendo por base as Tabelas 6 e 7 , observa-se que no tocante às vitaminas lipossolúveis analisadas ( $A, D$ e $E$ ) existe, nas duas regiões metropolitanas, uma tendência crescente de disponibilidade, conforme aumenta a renda salarial.

A vitamina A apresenta-se disponível em todos os estratos de renda nas duas RM, inclusive com níveis superiores ao recomendado (800 $\mu \mathrm{g})$. Na RM de Curitiba, as famílias dos estratos de renda mais elevado (acima de $30 \mathrm{SM}$ ), revelaram a maior disponibilidade $(5.461,0 \mu \mathrm{g})$ e a menor $(800,9 \mu \mathrm{g})$ foi verificada entre as famílias mais pobres (até $2 \mathrm{SM}$ ). Também na RM de Porto Alegre a menor $(1.983,6 \mu \mathrm{g})$ disponibilidade foi observada entre os mais pobres, ou seja, no estrato de renda até $2 \mathrm{SM}$ e a maior $(5.101,9 \mu \mathrm{g})$, entre as famílias do estrato com os maiores rendimentos (mais de $30 \mathrm{SM}$ ).

Velásquez-Melendéz et al. (1997) em uma pesquisa sobre o consumo de vitaminas e minerais, tendo como amostra, adultos residentes em área metropolitana de São Paulo, encontraram valores inferiores de vitamina A (mediana de $496 \mu \mathrm{g} / \mathrm{dia}$ ), quando comparado com o presente estudo. D'Alambert (2000) em sua pesquisa envolvendo adultos da região metropolitana de São Paulo, sobre o consumo de vitaminas antioxidantes (especificamente a vitamina A), observou um valor mediano de $1.747 \mu \mathrm{g} / \mathrm{dia}$.

Estudo para avaliar a disponibilidade de carotenóides nas RM de Curitiba e Salvador, revelou que há elevação do conteúdo de nutriente conforme aumenta 0 rendimento. Ao analisar especificamente alguns tipos de carotenóides, os resultados foram favoráveis à RM de Curitiba em relação a beta-criptoxantina, luteína e zeaxantina, os quais encontram-se presente em maior proporção nas frutas e hortaliças folhosas e florais. Os referidos alimentos tiveram maior disponibilidade nos domicílios das famílias das RM de Curitiba quando comparados com a RM de Salvador. Por outro lado, a disponibilidade de beta-caroteno (proveniente de raízes, tubérculos e derivados) e licopeno (principalmente o tomate, melancia e caqui) foi maior na RM de Salvador (Padovani \& Amaya-Farfán, 2002). 
A vitamina $\mathrm{E}$ apresenta-se disponível em praticamente na totalidade dos domicílios, quando são consideradas as duas RM integrantes da presente pesquisa. Exceção é identificada na RM de Porto Alegre, quando se considera o grupamento de famílias do estrato de renda de mais de 20 a $30 \mathrm{SM}(9,9 \mathrm{mg}$, sendo o valor preconizado de $15 \mathrm{mg}$ ).

D'Alambert (2000) em seu estudo sobre vitaminas antioxidantes, verificou que a mediana de consumo da vitamina $E$ foi de $7,62 \mathrm{mg} / \mathrm{dia}$, resultado este distinto do observado nesta pesquisa.

Para as vitaminas hidrossolúveis, observa-se que a vitamina C (ácido ascórbico) atingiu o valor preconizado $(82,5 \mathrm{mg})$ somente para as famílias dos estratos com rendimentos acima de $30 \mathrm{SM}$ em ambas regiões (103,5 mg para Curitiba e 83,8 mg para Porto Alegre). Em relação a essa vitamina, observou-se uma tendência crescente de disponibilidade domiciliar conforme a elevação da renda familiar. Este resultado foi semelhante ao encontrado por D'Alambert (2000) que encontrou mediana de $88,4 \mathrm{mg} /$ dia de consumo da referida vitamina.

Cabe destacar que os cálculos do valor nutricional, elaborados para viabilização das análises, tiveram por base informações registradas em tabelas cujos dados referem-se, na sua maioria, aos alimentos crus (especialmente no caso de hortaliças), não levando em consideração as perdas acarretadas por exemplo, pela cocção. De acordo com Silva (1996) essas perdas merecem atenção, tendo em vista que o ácido ascórbico é considerado elemento de notória essencialidade no aproveitamento do ferro alimentar (especialmente o ferro não-heme).

Ainda com relação ao ácido ascórbico, Silva (1990) analisou o conteúdo deste nutriente na dieta habitual do paulistano, mostrando que as perdas variavam de 22 a $56 \%$, conforme o modo de preparo adotado pelas famílias integrantes da pesquisa. Particularmente quanto ao tomate, o referido autor ressalta que, independentemente do tipo de preparo, foi verificado comportamento semelhante quanto à preservação do ácido ascórbico (66\% na 
forma refogada; $74 \%$ na cozida por cinco minutos e $62 \%$, quando cozida durante quinze minutos).

Silva \& Naves (2001) argumentam favoravelmente ao consumo de dietas ricas em frutas e hortaliças que forneçam cerca de $150 \mathrm{mg}$ de vitamina C, 30 mg de vitamina E e $4 \mathrm{mg}$ de carotenóides como estratégia de prevenção do câncer. Esses valores recomendados são superiores, quando comparados as RDA`s, uma vez que estas vitaminas são consideradas antioxidantes e portanto, exercem papel fundamental em atividades específicas nas células, sendo necessário maior conteúdo das mesmas em situações especificas.

Quanto às vitaminas do complexo $B$, observa-se que a tiamina (vitamina B1) e a riboflavina (vitamina B2) os resultados revelam valores próximos dos preconizados, para a totalidade dos estratos de renda.

Quanto à piridoxina (vitamina B6) foram identificados valores abaixo do preconizado (1,3 mg) somente para famílias da RM de Curitiba, nos estratos de renda de até $2 \mathrm{SM}(0,3 \mathrm{mg})$, mais de 10 a $15 \mathrm{SM}(1,0 \mathrm{mg})$ e no de mais de 30 $\mathrm{SM}(0,6 \mathrm{mg})$.

A vitamina B12 (cianocobalamina) apresenta-se disponível em quantidades adequadas, nos domicílios pertencentes às duas regiões, somente nos estratos de renda mais elevados (mais de 20 a 30 SM e mais de $30 \mathrm{SM}$ ). Nos demais estratos de renda, a referida vitamina apresenta-se com maior disponibilidade na RM de Curitiba. No entanto, deve merecer atenção a quantidade insuficiente da mesma.

A disponibilidade adequada de niacina aparece somente no estrato de rendimento mais elevado (acima de $30 \mathrm{SM}$ ), para ambas regiões $(18,9$ e $15 \mathrm{mg}$, para Curitiba e Porto Alegre, respectivamente).

A disponibilidade de folacina nos domicílios não atende as recomendações registradas na literatura, em nenhuma das duas regiões metropolitanas. Verifica-se que os valores são muito inferiores ao preconizado $(400 \mu \mathrm{g})$. Entre as famílias mais ricas (renda de mais de $30 \mathrm{SM}$ nas duas RM), 
foi observada maior disponibilidade $(97,6 \mu \mathrm{g}$ para Curitiba e $81,4 \mu \mathrm{g}$ para Porto Alegre).

Com relação ao ácido fólico, também deve ser considerado que ainda que este trabalho não tenha avaliado o consumo fora do domicílio, não significa que ocorra um incremento na disponibilidade do nutriente, pois além de ser encontrada em alimentos não consumidos rotineiramente pela população, esta vitamina é extremamente sensível ao calor e pouco resistente ao oxigênio e à luz (Vanucchi \& Jordão, 1998). Note-se que tais condições adversas são freqüentemente observadas nos estabelecimentos que comercializam refeições e portanto, não necessariamente favorecem, do ponto de vista nutricional, os consumidores que optam por esse tipo de serviço.

A folacina tem como função atuar como uma coenzima, fazendo a transferência de carbono de um composto para outro, sendo essencial ainda para a síntese de ácidos nucléicos e do metabolismo de certos aminoácidos (Euclydes, 1998). Por outro lado, a deficiência de ácido fólico produz anemia megaloblástica ou macrocítica, muito semelhante à anemia por deficiência da cobalamina (vitamina B12). Parece haver uma relação entre o folato e a reparação do DNA e a expressão de oncogenes, o que pode contribuir para a prevenção do câncer (Selhub \& Rosenberg, 1997).

Os alimentos constantes da dieta da população de um modo geral parecem não suprir as necessidades de ácido fólico, principalmente quando se considera a população que constitui grupo de risco (crianças, gestantes e idosos). Deste modo, é necessário a suplementação medicamentosa ou a fortificação de alimentos com esta vitamina, a fim de reduzir os riscos da doença.

O conteúdo de ácido pantotênico parece ser adequado (valor preconizado pela literatura especializada), quando se considera o domicílio das famílias das duas RM analisadas (National Academy of Sciences, 2003). Somente nos domicílios de famílias pertencentes aos estratos de até 2 SM e de 
mais de $30 \mathrm{SM}$, na RM de Curitiba foram observados menores conteúdos (1,0 mg e 1,8 mg, respectivamente).

$\mathrm{Na}$ presente pesquisa também foi analisada a disponibilidade nos domicílios dos seguintes minerais: sódio, potássio, cálcio, fósforo, magnésio, manganês, zinco, ferro, cobre, iodo e selênio. Os resultados foram reunidos nas Tabelas 8 e 9, apresentadas a seguir. 
Tabela 8. Disponibilidade de minerais nos domicílios das regiões metropolitanas de Curitiba e Porto Alegre (POA), de acordo com o estrato de recebimento familiar per capita (em salários mínimos), de até 2 SM até mais de 6 a 8 SM. 1995/1996

\begin{tabular}{|c|c|c|c|c|c|c|c|c|c|c|}
\hline \multirow{3}{*}{ Minerais } & \multicolumn{10}{|c|}{ Estrato de Recebimento (em salários mínimos) } \\
\hline & \multicolumn{2}{|c|}{ Até 2} & \multicolumn{2}{|c|}{ Mais de 2 a 3} & \multicolumn{2}{|c|}{ Mais de 3 a 5} & \multicolumn{2}{|c|}{ Mais de 5 a 6} & \multicolumn{2}{|c|}{ Mais de 6 a 8} \\
\hline & Curitiba & POA & Curitiba & POA & Curitiba & POA & Curitiba & POA & Curitiba & POA \\
\hline lodo $(\mu \mathrm{g})$ & 3,9 & 1,7 & 3,2 & 2,5 & 2,5 & 2,1 & 3,6 & 1,3 & 3,1 & 1,8 \\
\hline Sódio(mg) & 4,7 & 2,7 & 4,3 & 3,0 & 4,7 & 3,1 & 6,2 & 2,5 & 4,3 & 2,7 \\
\hline Cálcio(mg) & 220,1 & 160,9 & 187,9 & 237,1 & 216,2 & 208,9 & 263,7 & 199,0 & 248,6 & 266,2 \\
\hline Magnésio(mg) & 137,0 & 68,9 & 101,9 & 92,3 & 90,3 & 86,8 & 110,0 & 71,5 & 99,0 & 90,4 \\
\hline Zinco(mg) & 4,1 & 2,2 & 2,7 & 3,0 & 2,9 & 2,8 & 3,5 & 2,5 & 3,1 & 3,2 \\
\hline Manganês(mg) & 19,0 & 0,2 & 5,4 & 0,3 & 2,0 & 1,2 & 9,3 & 2,1 & 3,3 & 2,5 \\
\hline Potássio(mg) & 774,4 & 398,5 & 580,7 & 548,6 & 515,7 & 530,5 & 727,7 & 515,2 & 586,8 & 685,1 \\
\hline Fósforo(mg) & 572,7 & 413,6 & 455,4 & 515,5 & 483,2 & 548,3 & 571,2 & 396,6 & 565,3 & 510,6 \\
\hline Ferro (mg) & 8,1 & 8,4 & 7,9 & 10,4 & 7,5 & 17,6 & 10,9 & 16,8 & 8,9 & 15,9 \\
\hline Cobre(mg) & 40,3 & 19,0 & 33,5 & 27,7 & 26,9 & 25,3 & 35,1 & 16,7 & 32,1 & 21,1 \\
\hline Selênio(uq) & 27,2 & 23,2 & 22,5 & 29,1 & 27,2 & 27,5 & 33,0 & 29,3 & 30.0 & 33.3 \\
\hline
\end{tabular}

Fonte: Bleil (2004) baseado em IBGE (1998) 
Tabela 9. Disponibilidade de minerais nos domicílios das regiões metropolitanas de Curitiba e Porto Alegre (POA), de acordo com o estrato de recebimento familiar per capita (em salários mínimos), de mais de 8 a $10 \mathrm{SM}$ até mais de 30 SM. 1995/1996

\begin{tabular}{|c|c|c|c|c|c|c|c|c|c|c|}
\hline \multirow{3}{*}{ Minerais } & \multicolumn{10}{|c|}{ Estrato de Recebimento (em salários mínimos) } \\
\hline & \multicolumn{2}{|c|}{ Mais de 8 a 10} & \multicolumn{2}{|c|}{ Mais de 10 a 15} & \multicolumn{2}{|c|}{ Mais de 15 a 20} & \multicolumn{2}{|c|}{ Mais de 20 a 30} & \multicolumn{2}{|c|}{ Mais de 30} \\
\hline & Curitiba & POA & Curitiba & POA & Curitiba & POA & Curitiba & POA & Curitiba & POA \\
\hline Iodo $(\mu \mathrm{g})$ & 2,5 & 1,6 & 2,4 & 2,0 & 3,1 & 2,1 & 2,5 & 1,1 & 3,8 & 1,6 \\
\hline Sódio (g) & 4,3 & 3,3 & 4,2 & 2,9 & 4,9 & 2,8 & 3,6 & 1,8 & 5,0 & 2,5 \\
\hline Cálcio (mg) & 223,6 & 228,8 & 283,2 & 254,2 & 282,6 & 238,8 & 312,8 & 294,9 & 374,2 & 345,2 \\
\hline Magnésio (mg) & 104,6 & 85,4 & 107,2 & 96,2 & 122,2 & 106,9 & 124,3 & 90,5 & 142,8 & 109,5 \\
\hline Zinco (mg) & 4,0 & 3,3 & 4,2 & 3,7 & 4,1 & 4,3 & 4,8 & 4,6 & 6,0 & 5,4 \\
\hline Manganês (mg) & 3,2 & 0,9 & 11,1 & 1,5 & 9,8 & 2,2 & 4,3 & 1,3 & 10,1 & 2,1 \\
\hline Potássio (mg) & 707,1 & 575,3 & 841,1 & 706,7 & 896,7 & 783,0 & 941,6 & 814,0 & 1194,1 & 1031,9 \\
\hline Fósforo (mg) & 535,7 & 494,7 & 659,1 & 542,8 & 606,4 & 623,9 & 701,8 & 573,9 & 827,4 & 711,6 \\
\hline Ferro (mg) & 8,9 & 15,2 & 9,5 & 9,5 & 11,0 & 10,4 & 10,3 & 8,8 & 11,4 & 9,8 \\
\hline Cobre (mg) & 22,1 & 18,9 & 22,6 & 21,8 & 31,4 & 21,9 & 23,2 & 11,7 & 31,8 & 16,3 \\
\hline Selênio $(\mu \mathrm{g})$ & 34,2 & 30,0 & 40,0 & 38,8 & 39,9 & 42,9 & 44,4 & 48,8 & 55,3 & 50,4 \\
\hline
\end{tabular}

Fonte: Bleil (2004) baseado em IBGE (1998) 
O conteúdo de sódio apresenta-se disponível em quantidade inferior, quando se considera o valor preconizado $(4 \mathrm{~g}$ ) e também a totalidade do estrato de renda da RM de Porto Alegre. Quando se considera a RM de Curitiba, apenas as famílias pertencentes ao estrato de renda de mais de 20 a $30 \mathrm{SM}$ não se beneficiaram de conteúdo considerado ideal (aproximadamente 3,5 $\mathrm{mg} / \mathrm{dia}$ ). Cabe ressaltar mais uma vez que o consumo de alimentos fora do domicílio não foi analisado e portanto o conteúdo total disponível para os indivíduos pode ser ainda mais elevado.

Cabral et al. (2003) realizaram uma avaliação dietética, tendo como amostra hipertensos atendidos em hospital universitário. Os autores concluíram que o consumo diário de sódio era elevado - $4 \mathrm{~g} / \mathrm{dia}$ em média. Note-se que foi considerado exclusivamente o sal adicionado e não os outros alimentos considerados fontes expressivas de sódio, como enlatados, embutidos, condimentos, etc.

Por outro lado a disponibilidade de potássio não supre a recomendação ( $2 \mathrm{~g}$ ) para as famílias das duas Regiões Metropolitanas. Os melhores resultados foram encontrados para as famílias mais ricas (1,2 g para Curitiba e 1,0 $\mathrm{mg}$ em Porto Alegre). No entanto, ressalta-se que os valores podem ser classificados como indicativo de reduzido consumo.

Com relação ao cálcio, foi encontrada situação muito semelhante à verificada para o potássio, ou seja, em nenhuma RM a disponibilidade atingiu o conteúdo médio recomendado. Observa-se ainda uma discreta disponibilidade deste mineral conforme a renda aumenta, quando são consideradas as duas RM. Cabe salientar que maior disponibilidade foi observada para famílias de renda mais elevada (mais de $30 \mathrm{SM}$ ) das duas RM. Note-se, contudo, que a disponibilidade atende cerca de $1 / 3$ do valor recomendado, quando são considerados, por exemplo, indivíduos adultos (1000 mg/dia). Na RM de Curitiba a disponibilidade de cálcio para o grupamento de famílias mais ricas (mais de $30 \mathrm{SM}$ ), a disponibilidade é de $374,2 \mathrm{mg}$ e na RM de Porto Alegre, alcança $345,2 \mathrm{mg}$. 
A deficiência de cálcio apresenta-se como um dos fatores que contribuem para o aparecimento da osteoporose e muitas pesquisas têm identificado essa associação, principalmente entre mulheres na pósmenopausa. Segundo Lanzillotti et al. (2003) tendo por base um estudo envolvendo mulheres na pós-menopausa que apresentavam problemas de osteoporose ou osteopenia, verificaram um consumo $(630,15 \mathrm{mg})$ diário de cálcio abaixo do recomendado.

Pesquisa realizada em Florianópolis/SC, com o envolvimento de mulheres na pós-menopausa, foi identificado um baixo consumo (58\% do recomendado) de cálcio em mulheres, diagnosticadas com osteoporose. (Borges, Di Pietro \& Moretto, 2000).

Cabral et al. (2003), desenvolveram pesquisa com hipertensos com idade entre 18 e 74 anos, identificando baixa ingestão de cálcio (média de 681 $\mathrm{mg} / \mathrm{dia}$ ). No entanto, o conteúdo ingerido se revelou maior, quando comparado com os resultados obtidos no presente estudo.

Weaver, Peacock e Johnston Junior (1999) relatam que a nutrição inadequada na puberdade resulta em inadequado pico de crescimento ósseo, o qual aumenta os riscos de fraturas ósseas no futuro. Esses autores registram que a ingestão de produtos ricos em cálcio, magnésio, fósforo e vitamina $D$ contribuem para evitar a osteoporose.

Uma outra doença, já mencionada anteriormente, cuja prevalência vem crescendo entre a população brasileira é a osteoporose, e está freqüentemente associada ao envelhecimento. Atualmente, a osteoporose é reconhecida como enfermidade de importância social e econômica, devido à dificuldade dos pacientes na condução de tratamentos prolongados e, invariavelmente, com envolvimento de custos elevados. Somado a freqüente impossibilidade para o trabalho, ocorre geralmente uma redução nos ganhos salariais, o que reflete diretamente no consumo alimentar (Lerner et al., 2000).

A disponibilidade de fósforo observada na presente pesquisa apresentase um pouco acima do recomendado, quando comparada ao conteúdo de 
cálcio. Contudo, os valores verificados atingem a recomendação média apenas para famílias com maiores rendimentos. Para as famílias do estrato de mais de 5 a 6 SM na RM de Porto Alegre, foi observada a menor disponibilidade do fósforo (396,6 mg).

Vale destacar que o fósforo, quando ingerido em maior proporção que o cálcio, inibe a absorção deste (Lanzillotti et al., 2003).

A disponibilidade de magnésio nas RM de Curitiba e Porto Alegre apresenta-se muito abaixo do recomendado (370 mg), não atingindo $50 \%$ do valor preconizado, por exemplo para os adultos. Os melhores resultados foram encontrados para as famílias da RM de Curitiba e dos estratos de até 2 SM (137,0 mg) e mais de $30 \mathrm{SM}(142,8 \mathrm{mg})$.

Cabe registrar que o magnésio parece ter relação com a ação e secreção da insulina, por isso a sugestão de que a deficiência de magnésio está relacionada com a resistência à insulina no Diabetes Mellitus (Reis, Velloso e Reyes, 2002)

Para o manganês, verifica-se uma discrepância nos resultados, com valores que delimitam extremos de 0,2 $\mathrm{mg}$ até $19 \mathrm{mg}$, observado no estrato de menor renda (até 2 SM) para a RM de Curitiba e Porto Alegre, respectivamente. Tal situação também foi observada quando se analisou o lodo.

É baixa a disponibilidade de zinco para as famílias de todos os estratos de renda, nas duas RM. Assim como o cálcio parece que a renda exerce influência no conteúdo disponível do referido nutriente. Este resultado pode ser decorrente do fato que as melhores fontes de zinco encontram-se nos produtos de origem animal, e conforme aumenta o poder aquisitivo da população, aumenta também $\mathrm{o}$ acesso a estes alimentos. Cabe registrar que a disponibilidade se revelou mais elevada para as famílias mais ricas (mais de 30 $\mathrm{SM}$ ), das duas RM (6,0 mg para Curitiba e 5,4 mg para Porto Alegre). Contudo, frisa-se que o resultado ainda é inferior ao valor $(9,5 \mathrm{mg})$ recomendado pela literatura (National Academy of Sciences, 2003). 
O ferro é outro mineral de fundamental importância para o organismo. Para o estabelecimento de análises comparativas, foi definido o valor médio de $13 \mathrm{mg} / \mathrm{dia}$ que atende as recomendações de, por exemplo, indivíduo adulto na faixa etária de 31 a 50 anos. Os resultados revelam que a menor disponibilidade ocorreu entre as famílias pobres (mais de 2 a 3 SM) na RM de Curitiba (7,9 mg) e a maior (17,6 mg) na RM de Porto Alegre, no estrato de renda de mais de 3 a $5 \mathrm{SM}$. Observa-se ainda que na RM de Porto Alegre as famílias têm à disposição maior conteúdo de ferro, especialmente aquelas pertencentes aos menores estratos de renda (de até 2 SM até mais de 8 a 10 SM). Por outro lado, as famílias da RM de Curitiba apresentam vantagem relativa, quando comparadas com os três grupamentos de maior renda da RM de Porto Alegre.

O Estudo Multicêntrico de Consumo Familiar de Alimentos, desenvolvido nos anos de 1996/1997, revelou que no município de Curitiba (PR), o percentual de consumo de ferro não atingiu $50 \%$ do recomendado pela Recommended Dietary Allowances (RDA/1989), especialmente quando foi considerado o grupo com idade entre 18 a 65 anos (Galleazzi, Domene e Sichieri, 1997). Note-se que o resultado obtido pelos referidos autores se distingue dos valores observados na presente pesquisa.

Um dos maiores problemas de saúde pública, principalmente em países em desenvolvimento relaciona-se à deficiência de ferro, que invariavelmente leva à anemia ferropriva. Esta deficiência tem atingido especialmente crianças, adolescentes, gestantes e idosos, podendo ser considerado um dos fatores condicionantes do baixo peso em recém nascidos, prematuridade, redução na capacidade de trabalho e baixa imunidade (Ybarra, Costa e Ferreira, 2001).

As principais causas do alto índice de anemia ferropriva são a ingestão insuficiente, a baixa biodisponibilidade do ferro ingerido por meio da alimentação, seguidas das infecções e parasitoses intestinais. Também a baixa renda, práticas alimentares inadequadas, analfabetismo e a ineficácia das políticas de alimentação e nutrição, podem contribuir para a deficiência de ferro 
na população. As conseqüências da deficiência do mineral são danosas para o organismo, pois o transporte de oxigênio para os tecidos poderá ser comprometido, decorrente principalmente da redução na concentração de hemoglobina. A fadiga, a irritabilidade e a anorexia são sintomas característicos da baixa disponibilidade de ferro nos tecidos (Chaud et al., 2000).

Cabe lembrar que a prevalência mundial de anemia é estimada em aproximadamente 30\%. Dados da Organização Mundial da Saúde - OMS referem que, no mundo $50 \%$ das mulheres em idade reprodutiva e adolescentes apresentam deficiência de ferro. Na América Latina, a taxa média de anemia em mulheres não grávidas é estimada em $30 \%$, devido principalmente as perdas mensais decorrentes da menstruação (Rodriguéz et al., 2001)

No que diz respeito aos alimentos fontes do referido mineral, cabe destacar que as melhores fontes de ferro são provenientes do ferro heme (origem animal), seguidos do ferro não heme (origem vegetal). Embora os alimentos de origem vegetal possuam conteúdos apreciáveis de ferro, sua absorção pelo trato digestório é menos eficiente, pois vários são os fatores que podem inibir sua presença, conforme citado anteriormente (Euclydes, 1998).

Cabe destacar ainda que os resultados apresentados no presente estudo sugerem uma razoável disponibilidade média de ferro. Por outro lado, os inúmeros estudos de base populacional, demonstram que no Brasil a anemia por deficiência de ferro ainda é considerada um grande problema, demandando intervenções em curtíssimo prazo.

Os países desenvolvidos têm conseguido diminuir o problema de anemia carencial, por meio da fortificação de produtos com vitaminas e minerais, principalmente por iniciativas pioneiras das indústrias de alimentos que cada vez mais tem procurado ofertar ao consumidor, alternativas para aumentar o consumo de seus produtos (Ybarra, Costa e Ferreira, 2001).

Em nosso país, ainda que muitos estudos demonstrem a elevada prevalência de anemia, os mesmos são restritos a algumas áreas específicas e também a grupos da população, o que tem contribuído para que insuficientes 
medidas de combate à anemia tenham sido efetivadas nos últimos tempos, tanto pelo governo como por iniciativa das indústrias de alimentos.

No tocante à disponibilidade de cobre os resultados da presente pesquisa revelam situação que pode ser classificada como satisfatória para as famílias das duas regiões metropolitanas e para a totalidade dos estratos de renda. No entanto, cabe registrar que a menor disponibilidade foi identificada na RM de Porto Alegre, entre as famílias do estrato de renda de mais de 20 a 30 SM (11,7 mg). Cabe frisar, que o valor recomendado para um indivíduo adulto é $9 \mathrm{mg}$.

O selênio, reconhecido como um mineral que exerce função antioxidante, apresentou resultados preocupantes, quando foram considerados os dados das famílias das duas RM estudadas. Apenas as famílias dos estratos de maior rendimento (mais de $30 \mathrm{SM}$ ) da RM de Curitiba, atingiram o valor recomendado $(55 \mu \mathrm{g})$. Para todas as famílias, os resultados observados foram inferiores ao preconizado. Por outro lado, observa-se que existe uma tendência de maior disponibilidade deste mineral, conforme ocorre crescimento da renda.

Faganello (2002), analisando os dados da POF 1995/1996, encontrou uma baixa disponibilidade de zinco, cálcio, ferro e selênio nos domicílios das famílias das RM de São Paulo e Recife.

Velásquez-Melendéz et al. (1997) realizaram uma pesquisa sobre o consumo de vitaminas e minerais, tendo como base amostral um grupo de indivíduos adultos da região metropolitana de São Paulo e concluíram que a ingestão destes nutrientes não poderia ser classificada como inadequada. No entanto, cabe registrar que os idosos apresentaram menor consumo. Tal informação alerta para o risco de diversas doenças crônicas, uma vez que essas deficiências são fatores contribuintes para os agravos da saúde. Sendo assim, é importante analisar o consumo de vegetais e frutas, registrado pela população brasileira, e também, identificar se a população tem acesso a estes alimentos ou hábito de adquiri-los. Tais informações são úteis para que seja possível propor alternativas como por exemplo, às relativas ao consumo, tendo 
em vista que há reconhecimento que a prevalência de doenças crônicas, entre elas o câncer, tem aumentado de forma substancial.

Pesquisa realizada por Millen et al. (1997), envolvendo amostra de adultos, revela que os níveis de ingestão de um conjunto de nutrientes essenciais se encontravam abaixo do recomendado, com destaque para o betacaroteno, vitamina E, vitamina B6, cálcio e fibras. Os autores registram a necessidade da implementação de estratégias de intervenção e práticas educativas, a fim de melhorar o estado nutricional da população.

As análises de vitaminas e minerais elaboradas na presente pesquisa indicam a inadequação alimentar pela qual a população brasileira tem convivido nas últimas décadas. 


\section{CONCLUSÕES}

Os dados da presente pesquisa indicam que a renda é um importante fator na disponibilidade alimentar da população das Regiões Metropolitanas de Curitiba e Porto Alegre, principalmente quando se considera o conteúdo energético total disponível nos domicílios. Por outro lado, pode-se afirmar que o aumento da renda não necessariamente pressupõe uma melhoria no acesso a alimentos adequados, tendo por base o valor nutricional.

Com relação aos macronutrientes, a presente pesquisa parece indicar uma tendência semelhante à observada nas demais regiões do país. Os carboidratos apresentam maior participação no VET disponível nos domicílios da população mais pobre nas duas regiões estudadas. Por outro lado, a participação dos lipídeos e proteínas revela aumento conforme cresce a renda.

Outro dado importante refere-se à elevada participação de proteína de origem animal, superando os valores preconizados, quando se analisou os dados das famílias pertencentes a totalidade dos estratos de renda. Este resultado pode contribuir para a evolução de doenças crônicas, consideradas até pouco tempo, patologias que atingiam a população, quase que exclusivamente, de países desenvolvidos.

Com relação à disponibilidade de alimentos de acordo com a origem (industrializado e in natura), observa-se que, para as famílias integrantes da amostra, há um predomínio da participação no VET dos alimentos industrializados (aproximadamente $80 \%$ ), isto sem levar em consideração a contribuição proveniente do consumo alimentar fora do domicílio. A disponibilidade de frutas, hortaliças e feijão não indicam diferenças 
expressivas entre as famílias, quando se considera a categoria de renda a que pertencem. Tal observação sugere que a população adota um hábito típico das regiões altamente urbanizadas, optando pelo consumo de produtos industrializados e evidentemente de mais fácil preparo.

Quando se analisa a contribuição dos grupos alimentares para o VET diário das famílias das duas regiões metropolitanas, observa-se uma participação expressiva dos cereais, principalmente nos estratos de menor renda. Por outro lado, a participação do grupo das carnes e embutidos e leite e derivados revela-se superior para as famílias com maiores rendimentos.

As leguminosas, especialmente o feijão, participam com maior disponibilidade no VET dos domicílios com menor renda, o que sugere que a população tende a diminuir o consumo de alimentos tradicionais, situação considerada típica dos centros altamente urbanizados.

A participação de verduras e legumes no VET, não apresenta diferença expressiva quando se considera os dez estratos de renda e as regiões metropolitanas. Por outro lado, as frutas aparecem em ligeira superioridade em relação às hortaliças, com tendência crescente na sua participação, conforme aumenta os rendimentos.

Os grupos dos açucares e doces e óleos e gorduras vegetais contribuem, cada um, com aproximadamente 13\% do VET diário das famílias, sendo inferior somente à participação do grupo dos cereais.

A participação do grupo da banha, toucinho, maionese e creme de leite, bem como dos refrigerantes e bebidas alcoólicas apresentaram contribuição semelhante, independente do estrato de renda das famílias.

Com relação às fibras, sua disponibilidade para as famílias estudadas se apresenta abaixo do valor preconizado, em ambas regiões e nos dez estratos de renda. Por outro lado, a disponibilidade do colesterol dietético não atingiu os valores aceitáveis, o que pode ser considerado, em parte, um resultado positivo, uma vez que atualmente, tem sido muito destacada a necessidade de estimular a redução do consumo de colesterol dietético a fim de evitar possíveis 
doenças correlacionadas a sua ingestão excessiva. No entanto, cabe lembrar que não foi avaliada a contribuição oriunda do consumo de alimentos fora do domicílio.

Em relação às vitaminas, nota-se que as vitaminas $A, E$, riboflavina, tiamina, piridoxina e ácido pantotênico revelaram contribuição que pode ser classificada como razoável para as famílias das duas regiões e praticamente para a maioria dos estratos de renda. Porém, os conteúdos de vitamina C, niacina e vitamina B12 podem ser considerados suficientes somente para as famílias mais ricas. Cabe ressaltar que o ácido fólico não atende de forma razoável às demandas da totalidade das famílias, atingindo apenas $25 \%$ do preconizado.

Com relação aos minerais, o sódio apresenta maior disponibilidade para as famílias da RM de Curitiba, superando o valor considerado aceitável. Na RM de Porto Alegre, a disponibilidade média deste mineral é menor. Porém, deve ser ressaltado que o consumo de alimentos fora do domicílio não foi analisado, o que certamente contribuiria para um conteúdo adicional do mesmo.

O cálcio também apresentou disponibilidade aquém (cerca de 30\%) do recomendado para a totalidade das famílias das duas RM.

A disponibilidade do ferro é superior na RM de Porto Alegre e, principalmente, para as famílias pertencentes aos maiores estratos de renda.

Com relação ao magnésio e zinco, os valores identificados foram inferiores ao preconizado, em ambas regiões e para a totalidade das famílias. Por outro lado, o conteúdo de cobre se aproximou da recomendação.

A disponibilidade do selênio se revelou satisfatória somente para as famílias pertencentes aos estratos de maior renda e moradoras da RM de Curitiba.

Face ao exposto, é importante ressaltar que a população tem revelado mudanças no seu padrão alimentar, em decorrência de inúmeros fatores, amplamente registrados nesta pesquisa. Por outro lado, outros estudos têm revelado que existe um incremento de doenças associadas com a alimentação 
inadequada. Sendo assim, é de fundamental importância que sejam buscadas alternativas para melhorar os hábitos e o padrão de consumo da população, de todas as classes socioeconômicas. Merece ênfase o desenvolvimento de novos produtos, como por exemplo, menor teor de gordura, sal e açúcar e acrescidos de nutrientes indispensáveis a manutenção adequada do organismo e ainda a implementação de programas que visem o estímulo do consumo de alimentos in natura, como por exemplo frutas e hortaliças.

Com a divulgação dos dados da nova POF, prevista para o final de 2004, será possível analisar a evolução temporal da disponibilidade de energia e nutrientes para as famílias da Região Sul do Brasil, além das novas regiões e setores incorporados à nova pesquisa de orçamentos familiares. 


\section{REFERÊNCIAS BIBLIOGRÁFICAS:}

ALMEIDA, L.M.; COUTINHO, E.S.F. Prevalência de consumo de bebidas alcoólicas e de alcoolismo em uma região metropolitana do Brasil. Revista de Saúde Publica, v.27, n.1, p.23-29, fev. 1993.

ANGELIS, R.C. Fome oculta: bases fisiológicas para reduzir seus riscos através de alimentação saudável. São Paulo: Atheneu, 2000. 236p.

BARRETO, S.A.J.; CYRILLO, D.; COZZOLINO, S.M.F. Análise nutricional e complementação alimentar de cesta básica derivada do consumo. Revista de Saúde Pública, v.32, n.1, p.29-35, fev. 1998.

BARROS, M.S.C. Programa de renda mínima como alternativa para uma política de alimentação e nutrição. Araraquara, 2000. 122p. Dissertação (Mestrado) - Faculdade de Ciências Farmacêuticas, Universidade Estadual Paulista "Julio de Mesquita Filho".

BATISTA FILHO, M.; RISSIN, A. Transição nutricional no Brasil: tendências regionais e temporais. Cadernos de Saúde Pública, v.19, p.181-191, 2003. Suplemento 1.

BELIK, W.; SILVA, J.G.; TAKAGI, M. Políticas de combate a fome no Brasil. São Paulo em Perspectiva, v.15, n.4, p.119-129, dez. 2001. 
BENTON, D. Efeitos dos carboidratos na memória e cognição. In: INSTITUTO DANONE, São Paulo, 1996. Anais. São Paulo: USP/Instituto Danone,1996. p.1-6.

BERMUDEZ, O.I.; TUCKER, K.L. Trends in dietary patterns of Latin America populations. Cadernos de Saúde Pública, v.19, p.578-599, 2003. Suplemento 1.

BERTASSO, B.F. O consumo alimentar em regiões metropolitanas brasileiras: análise da pesquisa de orçamentos familiares - IBGE 1995/1996. Piracicaba, 2001. 109p. Dissertação (Mestrado) - Escola Superior de Agricultura "Luiz de Queiroz", Universidade de São Paulo.

BLEIL, S.I. Mudança de hábitos a partir da industrialização agroalimentar. Rio de Janeiro, 1998. 135p. Dissertação (Mestrado) - Universidade Federal Rural do Rio de Janeiro.

BORGES, M.R.; DI PIETRO, P.F.; MORETTO, E. Avaliação da ingestão alimentar de leite e cálcio de mulheres durante o climatério como fator de risco nutricional para a osteoporose na pós-menopausa. In: SIMPÓSIO SUL BRASILEIRO DE ALIMENTAÇÃO E NUTRIÇÃO: HISTÓRIA, CIÊNCIA E ARTE, Florianópolis, 2000. Anais. Florianópolis: UFSC, 2000. p.591594.

BRANCO, N.S.D.C. Análise da alimentação fora do domicílio de consumidores do centro comercial do município do Rio de Janeiro, RJ. Rio de Janeiro, 2000. 116p. Tese (Doutorado) - Faculdade de Engenharia de Alimentos, Universidade Estadual de Campinas. 
BURLANDY, L.; ANJOS, L.A. Acesso a vale-refeição e estado nutricional de adultos beneficiários do PAT no nordeste e sudeste do Brasil. Cadernos de Saúde Pública, v.17, n.5, p.1457-1464, nov./dez. 2001.

CABRAL, P.C.; MELO, A.M.C.A.; AMADO, T.C.F.; SANTOS, R.M.A.B. Avaliação antropométrica e dietética de hipertensos atendidos em ambulatório de um hospital universitário. Revista de Nutrição, v.16, n.1, p.61-71, jan./mar. 2003.

CARDOSO, E.; MARTINS, I.S.; FORNARI, L. et al. Alterações eletrocardiográficas e sua relação com fatores de risco para doença isquêmica do coração em população da área metropolitana de São Paulo. Revista da Associação Médica Brasileira, v.48, n.3, p.231-236, jul./set. 2002.

CERVATTO, A.M.; MAZZILLI, R.N.; MARTINS, I.S.; MARUCCI, M.F. Dieta habitual e fatores de risco para doenças cardiovasculares. Revista de Saúde Pública, v.31, n.3, p.227-235, 1997.

CHAUD, M.V.; BIGNOTO, L.M.; PAGANELLI, M.O. et al. Deficiência de ferro: causas e conseqüências. Saúde em Debate, v.2, n.4, p.13-22, 2000.

CORONELLI, C.L.S.; MOURA, E.C. Hipercolesterolemia em escolares e seus fatores de risco. Revista de Saúde Pública, v.37, n.1, p.24-31, fev. 2003.

CRAIG, W.J. Phytochemicals: guardians of our health. Journal of the American Dietetic Association, v.97, n.1, p.199-204, Oct.1997. 
D'ALAMBERT, F.C.G. Consumo alimentar de vitamina C, E e Beta-caroteno em população adulta da região metropolitana de São Paulo. São Paulo, 2000. 69p. Dissertação (Mestrado) - Faculdade de Ciências Farmacêuticas, Universidade de São Paulo.

DOMENE, S.M.A.; ZABOTTO, C.B.; MENEGUELLO, R. et al. Perfil nutricional de crianças e suas mães em bolsões de pobreza do município de Campinas, SP. Revista de Nutrição de Campinas, v.12, n.2, p.183-189, maio/ago. 1999.

EUCLYDES, M.P. Nutrição do lactente. Viçosa: UFV, 1998. 488p.

FACULDADE DE CIÊNCIAS FARMACÊUTICAS. Tabela brasileira de composição de alimentos: projeto integrado de composição de alimentos. http://www.fcf.usp.br/tabela/tbcamenu.php (10 jul. 2001)

FAGANELLO, C.R. Disponibilidade de energia e nutrientes para a população das regiões metropolitanas de Recife e São Paulo. Piracicaba, 2002. 113p. Dissertação (Mestrado) - Escola Superior de Agricultura "Luiz de Queiroz", Universidade de São Paulo.

FAO. The state of food and agriculture: economic impacts of transboundary plant pests and animal diseases. Rome, 2000. 329p. n.33.

FISBERG, M.; AMÂNCIO, O.M.S.; LOTTENBERG, A.M.P. O uso de refrigerante e a saúde humana. Separata de Revista Pediatria Moderna, v.28, n.6, p.1-8, jun. 2002. 
FORNÉS, N.S.; MARTINS, I.S.; HERNAN, M. et al. Food frequency consumption and lipoproteins serum levels in the population of urban area, Brazil. Revista de Saúde Pública, v.34, n.4, p.380-387, ago. 2000.

FRANCISCHINI, R.P.P.; PEREIRA, L.O.; FREITAS, C.S. et al. Obesidade: atualização sobre sua etiologia, morbidade e tratamento. Revista de Nutrição, v.13, n.1, p.17-28, jan./abr. 2000.

FRANCO, G. Tabela de composição química dos alimentos. 9.ed. São Paulo: Atheneu, 1992. 307p.

GALEAZZI, M.A.M.; TADDEI, J.A.C.; VIANNA, R.P.T. et al. Inquérito de consumo mensal de alimentos na detecção de famílias de risco nutricional: metodologia para avaliação do consumo alimentar domiciliar. Revista de Metabolismo e Nutrição, v.3, n.3, p.109-113. 1996.

GALEAZZI, M.A.M.; DOMENE, S.M.A.; SICHIERI, R. Estudo multicêntrico sobre consumo alimentar. Cadernos de Debate, p.17-25, 1997. Número especial.

GARCIA, R.W.D. Reflexos da globalização na cultura alimentar: considerações sobre as mudanças na alimentação urbana. Revista de Nutrição, v.16, n.4, p.483-492, dez. 2003.

GIROTTO, C.A.; VACCHINO, M.N.; SPILLMANN, C.A. et al. Prevalence of cardiovascular risk factors in first year university students. Revista de Saúde Pública, v.30, n.6, p.576-586, dez. 1996. 
HALPERN, A. Implicações fisiológicas e clínicas da diminuição da ingestão de carboidratos. In: INSTITUTO DANONE, São Paulo, 1996. Anais. São Paulo: USP/Instituto Danone, 1996. p.1-16.

HOFFMANN, R. A insegurança alimentar no Brasil. /Apresentado ao Seminário de Segurança Alimentar e Cidadania, Campinas, 1994/

HOFFMANN, R. A diminuição do consumo de feijão no Brasil. In: REUNIÃO DO CONSÓRCIO DAS INSTITUIÇÕES BRASILEIRAS DE ALIMENTAÇÃO E NUTRIÇÃO, São Paulo, 1995. Anais. São Paulo: CIBRAN, 1995. p.6-15.

INSTITUTO BRASILEIRO DE GEOGRAFIA E ESTATÍSTICA (IBGE). Estudo nacional de despesas familiares - ENDEF: 1974/1975. Rio de Janeiro,1978. 203p.

INSTITUTO BRASILEIRO DE GEOGRAFIA E ESTATÍSTICA (IBGE). Estudo nacional de despesas familiares: tabelas de composição de alimentos. 2.ed. Rio de janeiro, 1981. 213p.

INSTITUTO BRASILEIRO DE GEOGRAFIA E ESTATÍSTICA (IBGE). Pesquisa de orçamentos familiares 1995/1996: consumo alimentar domiciliar per capita. Rio de Janeiro, 1998. 139p.

KRITCHEVSKY, D.; BONFIEL, C.; ANDERSON, J.W. Dietary fiber: chemistry, physiology and healthy effects. New York: Plenum Press, 1988. 159p.

LAJOLO, F.M.; SAURA-CALIXTO, F.; PENNA, E.W. et al. Fibra dietética en Iberoamérica: tecnología e saúde. Livraria Varela: São Paulo. 2001. 469p. 
LANZILLOTTI, H.S.; LANZILLOTTI, R.S.; TROTTE, A.P.R.O. et al. Osteoporose em mulheres na pós-menopausa, cálcio dietético e outros fatores de risco. Revista de Nutrição, v.16, n.2, p.181-193, abr./jun. 2003.

LEAL, M.C.; BITTENCOURT, S.A. Informações nutricionais: o que se tem no país? Cadernos de Saúde Pública, v.13, n.3, p.551-555, jul./set. 1997.

LERNER, B.R. A alimentação e a anemia carencial em adolescentes. São Paulo, 1994. 112p. Tese (Doutorado) - Faculdade de Saúde Pública, Universidade de São Paulo.

LERNER, B.R.; LEI, D.L.M.; CHAVES, S.P. et al. O cálcio consumido por adolescentes de escolas públicas de Osasco, São Paulo. Revista de Nutrição, v.13, n.1, p.57-63, jan./abr. 2000.

LESSA, I.; CONCEIÇÃO, J.L.; SOUZA, M.L. Prevalência de dislipidemias em adultos da demanda laboratorial de Salvador, Brasil. Arquivos Brasileiros de Cardiologia, v.69, n.6, p.395-400, dez. 1997.

LIMA, F.E.L.; MENEZES, T.N.; TAVARES, M.P. et al. Ácidos graxos e doenças cardiovasculares: uma revisão. Revista de Nutrição, v.13, n.2, p.73-80, maio/ago. 2000.

LUSTOSA, T.Q.O.; FIGUEIREDO, J.B. Pobreza no Brasil: métodos de análise e resultados. Pesquisa e Planejamento Econômico, v.20, n.2, p.12-19, ago. 1990. 
MACHADO, F.M.S. Estratégias de concorrência da indústria alimentícia e seus desdobramentos na dimensão nutricional. São Paulo, 2003. 183p. Tese (Doutorado) - Faculdade de Ciências Farmacêuticas, Universidade de São Paulo.

MALUF, R. Consumo de alimentos no Brasil: traços gerais e ações públicas de segurança alimentar. São Paulo: Instituto Polis, 2000. 8p. (Série Papers, 6) http://www.polis.org.br/publicacoes/papers/20006.html (21 jul. 2004)

MARCHIONI, D.M.L.; ZACARELLI, E.M. Transição nutricional. Higiene Alimentar, v.16, n.96, p.16-22, maio 2002.

MARQUES, P.S. Parece sonho, mas é real. Alimentação e Nutrição, n.70, p.22-26, 1998.

MARTINS, E. Variações no consumo de alimentos no Brasil de 1974/75 a 1987/88. Piracicaba, 1998. 117p. Dissertação (Mestrado) - Escola Superior de Agricultura "Luiz de Queiroz", Universidade de São Paulo.

MATTOS, L.L.; MARTINS, I.S. Consumo de fibras alimentares em população adulta. Revista de Saúde Pública, v.34, n.1, p.50-55, 2000.

MENEZES, T.; SILVEIRA, F.G.; MAGALHÃES, L.C.G. et al. Gastos alimentares nas grandes regiões urbanas do Brasil: aplicação do modelo AID aos microdados da POF 1995/1996 IBGE. Brasília: IPEA, jul. 2002. (Texto para discussão, 896) 
MILLEN, B.E.; QUATROMONI, P.A.; FRANZ, M.M. et al. Population nutrient intake approaches dietary recommendations: 1991 to 1995 Framingham Nutrition Studies. Journal of the American Dietetic Association, v.97, n.7, p.742-748, 1997.

MONDINI, L. Desnutrição e obesidade no Brasil: relevância epidemiológica e padrões de distribuição intra-familiar em diferentes estratos econômicos e regionais. São Paulo, 1996. 98p. Tese (Doutorado) - Faculdade de Saúde Pública, Universidade de São Paulo.

MONDINI, L.; MONTEIRO, C.A. Mudanças no padrão de alimentação da população urbana brasileira: 1962-1988. Revista de Saúde Pública, v.28, n.6, p.433-439, 1994.

MONDINI, L.; MONTEIRO, C.A. Mudanças no padrão de alimentação. In: MONTEIRO, C.A. (Org.). Velhos e novos males da saúde no Brasil: a evolução do país e suas doenças. São Paulo: HUCITEC, 2000. cap.4, p.7989.

MONTEIRO, C.A.; MONDINI, L.; COSTA, R.B. Mudanças na composição e adequação nutricional da dieta familiar nas áreas metropolitanas do Brasil entre 1988 e 1996. In: MONTEIRO, C.A. (Org.). Velhos e novos males da saúde no Brasil. São Paulo: HUCITEC, 2000. cap. 21, p.359-374.

NATIONAL ACADEMY OF SCIENCES. Institute of Medicine. Food and Nutrition Board. Dietary reference intakes. Washington: National Academy Press, 2003. http://www.nap.edu (10 June 2003)

NEVES, E.M. Olhai a agricultura. Folha de São Paulo. Caderno 2, São Paulo, 10 jan. 1997. p.2. 
NEVES, M.F.; CHADDAD, F.; LAZZARINI, S.G. Alimentos: novos tempos e conceitos na gestão de negócios. São Paulo: Pioneira, 2000. 128p.

OLIVEIRA, S.P. Changes in food consumption in Brazil. Archivos Latinoamericanos de Nutricion, v.47, n.2, p.1-5, 1997.

OLIVEIRA, S.P.; THÉBAUD-MONY, A. Estudo do consumo alimentar: em busca de uma abordagem multidisciplinar. Revista de Saúde Pública, v.31, n.2, p.201-208, 1997.

OLIVEIRA, J.E.D; MARCHINI, J.S. Ciências nutricionais. São Paulo: Sarvier, 1998. 403p.

OLIVEIRA, S.P.; THÉBAUD-MONY, A. Hábitos e práticas alimentares em três localidades da cidade de São Paulo, Brasil. Revista de Nutrição, v.11, n.1, p.37-50, jan./jun. 1998.

ORGANIZAÇÃO PANAMERICANA DE SAÚDE (OPS). El Sur és la región más important. http://www.opas.gov.br (14 Jul. 2002)

PADOVANI, R.M.; AMAYA-FARFÁN, J. Disponibilidade de carotenóides nas regiões metropolitanas de Curitiba e Salvador. In: CONGRESSO BRASILEIRO DE CIÊNCIA E TECNOLOGIA DE ALIMENTOS: INTEGRAÇÃO PESQUISA INDÚSTRIA, 17., Porto Alegre, 2002. Anais. Porto Alegre: UFRGS, 2002. p.1323-1327.

PHILIPPI, S.T.; LATTERZA, A.R.; CRUZ, A.T.R. et al. Pirâmide alimentar adaptada: guia para escolha dos alimentos. Revista de Nutrição, v.12, n.1, p.65-80, jan./abr. 1999. 
PHILIPPI, S.T.; SZARFARC, S.C.; LATTERZA, A.R. Virtual nutri: versão 1.0 for windows (software). São Paulo: Universidade de São Paulo, Faculdade de Saúde Pública, Departamento de Nutrição, 1996.

REIS, M.A.B.; VELLOSO, L.A.; REYES, F.G.R. Alterações do metabolismo da glicose na deficiências de magnésio. Revista de Nutrição, v.15, n.3, p.333-340, 2002.

RIO GRANDE DO SUL. Secretaria de Estado da Saúde. Principais causas de mortalidade no Rio Grande do Sul. Porto Alegre, 2001. 8p.

ROCHA, S. As pesquisas nacionais sobre consumo no Brasil: objetivos e aplicações. In: INSTITUTO DANONE. Consumo alimentar: as grandes bases de informação. São Paulo: Instituto Danone, 1999. p.11-17.

RODRÍGUEZ, S.; BLANCO, A.; CUNNINGHAM, L. et al. Prevalência de las anemias nutricionales de mujeres em edad fértil. Costa Rica. Encuesta nacional de nutrición. 1996. Archivos Latinoamericanos de Nutrición, v.51, n.1, p.19-23, 2001.

ROSADO, E.L.; MONTEIRO, J.B.R. Obesidade e a substituição dos macronutrientes da dieta. Revista de Nutrição, v.14, n.2, p.145-152, maio/ago. 2001.

SARTORELLI, D.S.; FRANCO, L.J. Tendências do Diabetes Mellitus no Brasil: o papel da transição nutricional. Cadernos de Saúde Pública, v.19, p.529536, 2003. Suplemento 1.

SCHIRNDING, Y.V.; YACH, D. Unhealthy consumption threatens sustainable development. Revista de Saúde Pública, v.4, n.36, p.379-382, 2002. 
SELHUB, J.; ROSENBERG, I.H. Ácido fólico. In: ZIEGLER, E.E; FILER JUNIOR, L.J. Conocimientos actuales sobre nutrición. Washington: OPAS/OMS, 1997. cap.8, p.218-232.

SICHIERI, R.; CASTRO, J.F.G.; MOURA, A.S. Fatores associados ao padrão de consumo alimentar da população brasileira urbana. Cadernos de Saúde Pública, v.19, p.47-53, 2003. Suplemento 1.

SILVA, M.E.P. Teores de vitamina $\mathrm{C}$ em alimentos de consumo habitual na região de São Paulo. São Paulo, 1990. 71p. Dissertação (Mestrado) Faculdade de Ciências Farmacêuticas, Universidade de São Paulo.

SILVA, M.V. Produção e consumo de alimentos: a reflexão necessária. USP em Piracicaba, v.1, n.7, out. 1991.

SILVA, M.V. Estado nutricional de escolares matriculados em Centros Integrados de Educação Pública - CIEP's. São Paulo, 1996. 103p. Tese (Doutorado) - Faculdade de Saúde Pública, Universidade de São Paulo. São Paulo.

SILVA, M.V. Mudanças dos hábitos alimentares da população brasileira. Alimentação e Nutrição, v.18, n.71, p.40-49, 1998.

SILVA, M.V. Alimentos consumidos pelos alunos de escolas de tempo integral. Alimentação e Nutrição, v.11, n.60, p.89-110, 2000.

SILVA, C.R.M.; NAVES, M.M.V. Suplementação de vitaminas na prevenção de câncer. Revista de Nutrição, v.14, n.2, p.135-143, maio/ago., 2001. 
SILVEIRA, F.G.; MAGALHÃES, L.C.G.; TOMICH, F.A. et al. Insuficiência alimentar nas grandes regiões urbanas brasileiras. Brasília: IPEA, jun. 2002. (Texto para discussão, 884)

TASCO, A.M.P. Cesta básica. Conjuntura Alimentos, p.8-21, 1991. Número especial.

TIRAPEGUI, J. Nutrição: fundamentos e aspectos atuais. São Paulo: Atheneu, 2000. 284p.

TOMITA, L.Y; CARDOSO, M.A. Avaliação da lista de alimentos e porções alimentares de questionário quantitativo de freqüência alimentar em população adulta. Cadernos de Saúde Pública, v.18, n.6, p.1747-1756, nov./dez., 2002.

TRUDEAU, E.; KRISTAL, A.R.; LI, S. et al. Demographic and psychosocial predictors of fruit and vegetables intakes differ: implications for dietary interventions. American Journal of Dietetic Association, v.98, n.12, p.1412-1417, Dec. 1998.

VALENTE, F.L.S. Do combate a fome à segurança alimentar e nutricional: o direito à alimentação adequada. Revista de Nutrição, v.10, n.1, p.20-36, 1997.

VANUCCHI, H.; JORDÃO, J.R.A.A. Vitaminas hidrossolúveis. In: DUTRA-DEOLIVEIRA, J.E.; MARCHINI, J.S. Ciências nutricionais. São Paulo: Sarvier, 1998. cap.5, p.191-207. 
VANNUCHI, H.; MENEZES, E.W.; CAMPANA, A.O. et al. Aplicações das recomendações nutricionais adaptadas a população brasileira. São Paulo: Sociedade Brasileira de Alimentação e Nutrição, 1990. 115p.

VELOSO, I.S.; SANTANA, V.S. Impacto nutricional do programa de alimentação do trabalhador no Brasil. Revista Panamericana de Salud Pública, v.11, n.1, p.24-31, 2002.

VON DER HEYDE, M.E.; VON DER HEYDE, R.; VECHIA, A. et al. Região Sul. In: FISBERG, M.; WEHBA, J.; COZZOLINO, S.M. Um, dois, feijão com arroz: a alimentação no Brasil de Norte a Sul. São Paulo: Atheneu, 2002. cap.5, p.82-105.

WEAVER, C.M.; PEACOCK, M.; JOHNSTON JUNIOR, C. Adolescent nutrition in the prevention of posmenopausal osteoporosis. Journal of Clinical Endocrinology and Metabolism, v.84, n.6, p.1839-1943, 1999.

YBARRA, L.M.; COSTA, N.M.B.; FERREIRA, C.L.L.F. Interação cálcio e ferro: uma revisão. Nutrire, v.22, p.85-107, 2001. 
APÊNDICE 
APÊNDICE - Títulos dos modelos de registro para a coleta de informações de dados para Pesquisa de Orçamento Familiar (POF)

- Questionário do Domicílio - POF 1: utilizado para coleta de informações sobre abastecimento de água, esgoto, número de cômodos, condições de ocupação do domicílio, composição das unidades de consumo, sexo, nível de instrução e idade dos moradores.

- Questionário de Despesa Coletiva - POF 2: utilizado para obtenção de despesas com habitação, bens duráveis e outras.

- Caderneta de Despesa Coletiva - POF 3: registro pelo informante ou entrevistador, das despesas com alimentação, higiene e limpeza, realizados diariamente.

- Questionário de Despesa Individual - POF 4: adotado para obtenção dos gastos individuais. Para os gastos com alimentação fora do domicílio, as anotações foram feitas no Bloco de Anotações (instrumento auxiliar).

- Questionário de Recebimento Individual - POF 5: utilizado para obtenção de todos os rendimentos, recebimentos, receitas e empréstimos, bem como as principais deduções e encargos incidentes sobre os mesmos, e ainda informações sobre movimentação financeira de cada morador. 